\title{
A Quality by Design Framework for Capsule-Based Dry Powder Inhalers
}

\author{
Li Ding ${ }^{1}$, Ashlee D. Brunaugh ${ }^{1}$, Sven Stegemann ${ }^{2}{ }^{\mathbb{D}}$, Scott V. Jermain ${ }^{1} \mathbb{D}$, Matthew J. Herpin ${ }^{1}$, Justin Kalafat ${ }^{3}$ \\ and Hugh D. C. Smyth 1 ,* \\ 1 Division of Molecular Pharmaceutics and Drug Delivery, College of Pharmacy, \\ The University of Texas at Austin, Austin, TX 78712, USA; dingli@utexas.edu (L.D.); \\ ashbrunaugh@gmail.com (A.D.B.); sjermain15@utexas.edu (S.V.J.); matt.herpin@utexas.edu (M.J.H.) \\ 2 Institute for Process and Particle Engineering, Graz University of Technology, 8010 Graz, Austria; \\ sven.stegemann@tugraz.at \\ 3 ACG North America, LLC, 262 Old New Brunswick Road, Suite A, Piscataway, NJ 08854, USA; \\ justin.kalafat@acg-world.com \\ * Correspondence: hugh.smyth@austin.utexas.edu; Tel.: +1-505-514-9046
}

check for updates

Citation: Ding, L.; Brunaugh, A.D. Stegemann, S.; Jermain, S.V.; Herpin, M.J.; Kalafat, J.; Smyth, H.D.C. A Quality by Design Framework for Capsule-Based Dry Powder Inhalers. Pharmaceutics 2021, 13, 1213. https:// doi.org/10.3390/pharmaceutics13081213

Academic Editors: Stefano

Giovagnoli, Bo Olsson, Zachary

Warnken and Daniel Moraga-

Espinoza

Received: 10 July 2021

Accepted: 2 August 2021

Published: 6 August 2021

Publisher's Note: MDPI stays neutral with regard to jurisdictional claims in published maps and institutional affiliations.

Copyright: (c) 2021 by the authors. Licensee MDPI, Basel, Switzerland. This article is an open access article distributed under the terms and conditions of the Creative Commons Attribution (CC BY) license (https:/ / creativecommons.org/licenses/by/ $4.0 /)$.
Abstract: Capsule-based dry powder inhalers (cDPIs) are widely utilized in the delivery of pharmaceutical powders to the lungs. In these systems, the fundamental nature of the interactions between the drug/formulation powder, the capsules, the inhaler device, and the patient must be fully elucidated in order to develop robust manufacturing procedures and provide reproducible lung deposition of the drug payload. Though many commercially available DPIs utilize a capsule-based dose metering system, an in-depth analysis of the critical factors associated with the use of the capsule component has not yet been performed. This review is intended to provide information on critical factors to be considered for the application of a quality by design (QbD) approach for cDPI development. The quality target product profile (QTPP) defines the critical quality attributes (CQAs) which need to be understood to define the critical material attributes (CMA) and critical process parameters (CPP) for cDPI development as well as manufacturing and control.

Keywords: quality by design; inhalation capsule; dry powder inhalers; capsule activation; capsule manufacturing; capsule filling; capsule storage

\section{Introduction}

Dry powder inhalers (DPIs) are widely utilized for the treatment of multiple lung diseases including asthma [1], chronic obstructive pulmonary disorder (COPD) [2], cystic fibrosis (CF) [3], and CF-related Pseudomonas aeruginosa infections [4], virus-related lung infections [5] and systemic diseases like diabetes [6]. While various dose metering systems have been developed for DPIs, including blisters or reservoir-based devices [7], capsulebased DPIs (cDPIs) remain an important system for the therapeutic delivery of inhaled powders, with half of all DPIs on the market using this dose metering mechanism [8] (Table 1). cDPIs have been shown to provide accurate and consistent drug delivery [9] with multiple patient feedback mechanisms (e.g., visual, auditory) to assure that the dose was delivered [10]. 
Table 1. Examples of capsule-based DPIs available on the U.S. market and the drug(s) delivered by the device. Included also are the U.S. marketed products that utilize each device (if any) and the capsule in the FDA-approved formulation.

\begin{tabular}{|c|c|c|c|c|}
\hline Capsule-Based DPIs & Drug(s) Delivered & U.S. Marketed Product & Capsule Types & References \\
\hline Aerohaler $^{\circledR}$ & Ipratropium bromide & - & - & {$[8,11,12]$} \\
\hline Aerohaler ${ }^{\circledR} /$ Cyclohaler $^{\circledR}$ & $\begin{array}{l}\text { Formoterol fumarate * } \\
\text { Salbutamol sulfate } \\
\text { Beclomethasone } \\
\text { Dipropionate } \\
\text { Ipratropium bromide } \\
\text { Budesonide } \\
\text { Formoterol }\end{array}$ & Foradil ${ }^{\circledR}$ Aerohaler ${ }^{\circledR}$ & Gelatin & {$[8,11-15]$} \\
\hline Eclipse $^{\circledR}$ & Sodium cromoglycate & - & - & {$[13,15]$} \\
\hline FlowCaps ${ }^{\circledR}$ & $\mathrm{N} / \mathrm{A}$ & - & HPMC & [13] \\
\hline HandiHaler $^{\circledR}$ & Tiotropium bromide & SPIRIVA ${ }^{\circledR}$ HandiHaler ${ }^{\circledR}$ & Gelatin & {$[8,11-13,15]$} \\
\hline Inhalator $^{\mathrm{TM}}$ & Fenoterol & - & - & [11-13] \\
\hline Podhaler $^{\mathrm{TM}}$ & Tobramycin & TOBI $^{\mathrm{TM}}$ Podhaler $^{\mathrm{TM}}$ & HPMC & {$[8,15]$} \\
\hline Rotahaler $^{\circledR} /$ DPIhaler $^{\circledR}$ & $\begin{array}{l}\text { Salbutamol sulfate } \\
\text { Beclomethasone } \\
\text { Dipropionate }\end{array}$ & - & - & {$[8,11-13]$} \\
\hline RS01 & Mannitol & Aridol $^{\circledR}$ & Gelatin & {$[16,17]$} \\
\hline Spinhaler ${ }^{\circledR}$ & Sodium cromoglycate & Intal ${ }^{\circledR}$ Spincaps ${ }^{\circledR \dagger}$ & Gelatin & {$[8,11-13,15,18,19]$} \\
\hline Turbospin ${ }^{\circledR}$ & Colistimethate sodium & - & - & {$[8,15]$} \\
\hline \multirow{2}{*}{ Neohaler $^{\circledR}$} & Glycopyrrolate & Seebri $^{\mathrm{TM}}$ Neohaler ${ }^{\circledR}$ & HPMC & \multirow{2}{*}[8,15]{} \\
\hline & Indacaterol & Arcapta ${ }^{\circledR}$ Neohaler ${ }^{\circledR}$ & Gelatin & \\
\hline
\end{tabular}

${ }^{*}$ Indicates the drug present in the U.S. marketed product. ${ }^{\dagger}$ no longer available on the U.S. market.

The successful delivery of therapeutics from cDPI delivery systems involves a complex interplay of factors associated with the powder formulation, the formulation-capsule, and the device-capsule interactions. Consistency and predictability of the delivered dose to the patient are of great importance in product development and manufacturing of new chemical entities (NCE) or generic products. Demonstrating bioavailability and/or bioequivalence of DPI products remains an important product attribute for drug approval by the regulatory authorities [20]. Apart from pharmacologic reasons, failures in the development of NCE or generic inhaled therapies can stem from either a lack of understanding about aspects of the drug/formulation powder [21], device [22-24], and/or the mechanisms by which they interact. Several reviews have been published on DPI formulation design [25] or engineering strategy [26] as well as how the design [27] and characteristics [28] of DPI devices affect powder aerosolization performance revealing the multifactorial challenge of DPI products. This review seeks to expand these previously published analyses by providing insights into the critical material attributes (CMA) and critical process parameters (CPP) and hence critical quality criteria (CQA) to be considered for cDPI development and manufacture (Figure 1). Especially it relates to the inclusion of the capsule and device component as well as its metering system in order to provide further guidance on a QbD approach for the development of NCE or generic cDPI products. 


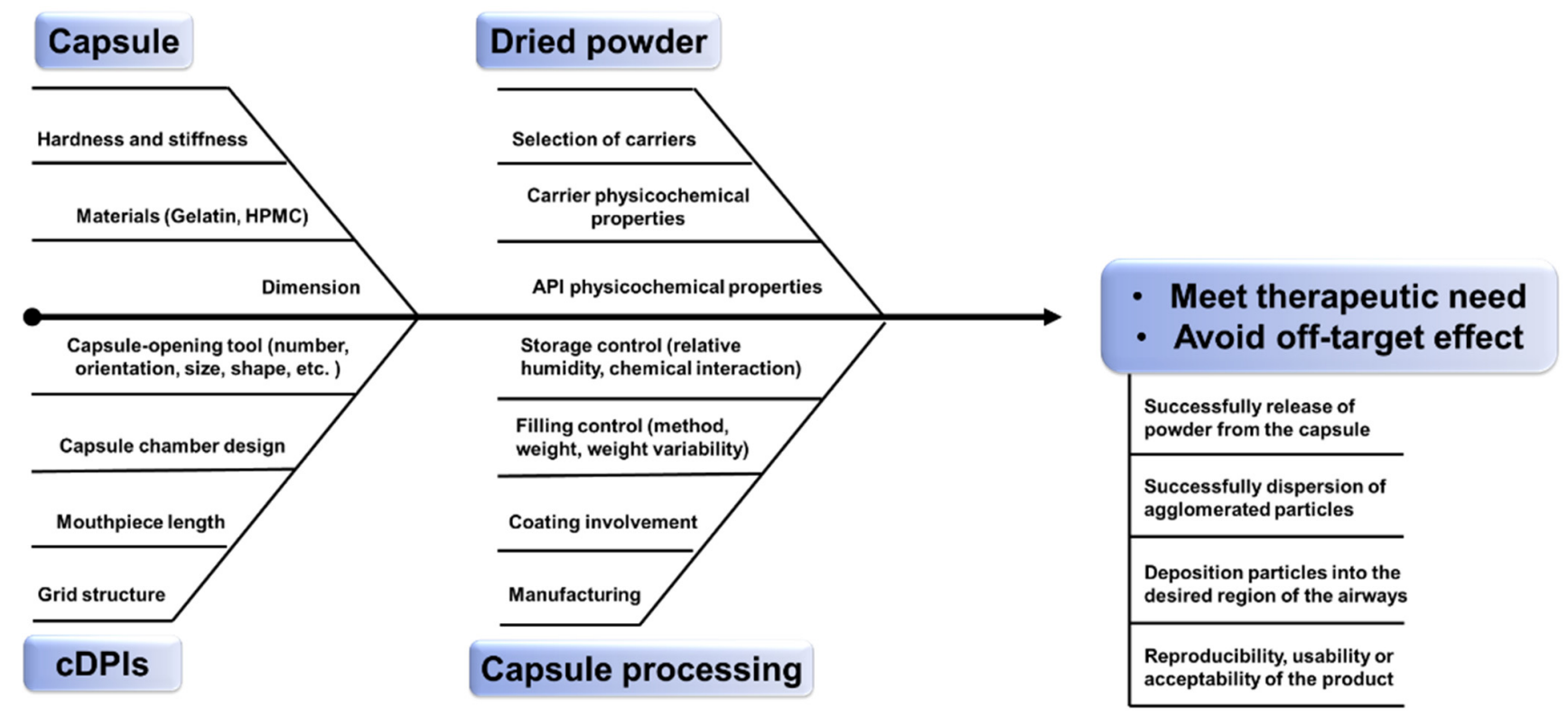

Figure 1. Quality by Design (QbD) framework of cDPIs.

\section{Overview of Quality by Design Approach for cDPIs}

As defined by the International Council for Harmonization's Q8R2 guideline, QbD is a "systematic approach to development that begins with predefined objectives and emphasizes product and process understanding and process control, based on sound science and quality risk management" (ICH Q8R2) [29]. A QbD approach is intended to generate sufficient product and process understanding that the robustness of the manufacturing process and the reproducibility of the clinical performance of the final drug product is assured. The basis of a typical $\mathrm{QbD}$ approach involves a clearly defined quality target product profile (QTPP), followed by a risk assessment in order to identify potential CQAs, CMAs, and CPPs of the process or product. The QTPP provides a comprehensive summary of all the required targets that will ensure the quality, safety, and efficacy of a specific product for the patient. The CQAs are the properties or characteristics of the product that should be within an appropriate limit, range, or distribution to ensure the desired product quality and performance (ICH Q8) [30]. The CMAs of the input materials and their properties can be identified, optimized, and controlled to ensure the desired quality of output materials [30]. A process parameter whose variability has an impact on a CQA and therefore should be monitored or controlled is termed as CPPs (ICH Q8) [30]. In addition, a number of design of experiments (DoEs) are performed to further delineate the design space and associated control strategies [31].

The delivery of drugs to the lungs via cDPI carries a unique set of quality and performance criteria that are unique to the pulmonary route of delivery. Depending upon the therapeutic indication, cDPIs may be utilized for the delivery of a variety of formulation systems including a binary mixture of large carrier particles and micronized drug particles, a carrier-free, high-dose $(>5-10 \mathrm{mg})$ drug formulations [32], or engineered particle using process technologies like spray drying [33]. Successful delivery of the drug to the lungs via cDPI involves the completion of several steps (Figure 2), including (1) capsule opening or piercing by the device, (2) release of powder from the capsule, (3) entrainment in the airflow, (4) dispersion of deaggregation of particles into primary particles or separation of carrier particles and drug particles, and (5) deposition of the drug particles into the desired region of the airways. The reproducibility of each of these steps and subsequently the reproducibly of the delivered dose and therapeutic effect is dependent upon patientassociated factors, such as inspiratory force or correct actuation of the device, as well as product factors like the initial raw material properties of the formulation components (e.g., particle shape, size, surface properties, crystallinity, moisture content of the excipients and 
drug) and capsule, the processing approach (e.g., milling, blending, spray drying, capsule filling), and the packaging and storage of the cDPI product.

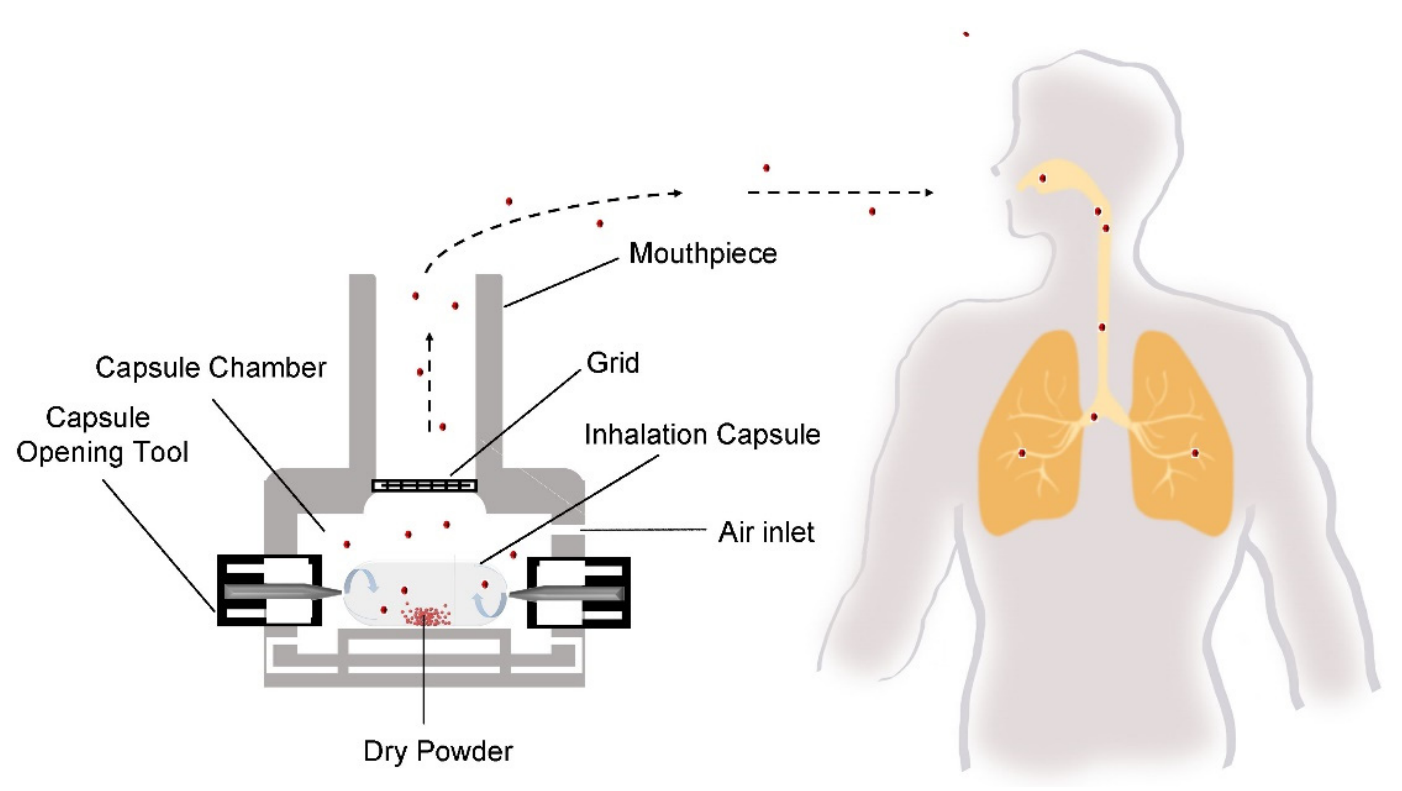

Figure 2. Schematic of an example of successful delivery of the drug to the lungs.

Essentially, the QTPP of cDPIs requires that the therapeutic need of the patient be met while avoiding off-target drug effects or toxicities. It is well known that lung deposition of therapeutic particles is challenging and depends upon many factors including drug formulation factors, device, patient parameters, and also the disease state. The requirement for systemic or targeted/topical therapeutic effect must also be considered with regard for the desired location of drug deposition. In case cDPIs are being used to achieve systemic therapeutic effects, it is likely to require deposition in the large-surface area, capillarity-rich region of the alveoli [34]. In fixed-dose combination therapy cases, where a synergistic effect is required the deposition efficiency and location of each drug in the formulation are even more important [35].

The approach to the pharmaceutical development described by the ICH Q8 (R2) guideline states that: "In all cases, the product should be designed to meet patients' needs and the intended product performance." Consequently, in addition to pharmacologicbased adverse drug reactions or toxicities, any other factor that reduces the usability or acceptability of the product by the patient should be considered [36]. For example, detachment of capsule pieces and subsequent inhalation by the patient may result in fragment deposition in the throat [37]. Variability in aerosol performance may result in unintended off-target effects of potent drugs, as noted in the case of inhaled insulin [38] or gene therapy agents [39]. Likewise, an unexpected increase in oropharyngeal deposition of drugs that are intended for lung-targeted therapeutic effects may result in the occurrence of systemic side effects [40].

\section{Critical Material Attributes (CMAs) in cDPIs}

As with other inhaled drug delivery systems, the critical CQAs of cDPIs to achieve the aforementioned QTPP are related to the delivery of a consistent fine particle dose of the drug in a manner that is robust to deviations in patient-related factors. These CQAs are in turn dependent upon CMAs associated with the cDPI, which should be controlled or limited [41]. Specific to CDPIs, CMAs relate to API and excipients including the material properties and design of the capsule, the capsule piercing/powder release mechanism present in the device, and the interaction of the powder formulation with the capsule. 


\subsection{CMAs Related Capsule Properties}

\subsubsection{Capsule Material}

Typically, cDPIs use hard-shell capsules to deliver dry powders to the lung. The hard-shell capsule is comprised of two open-ended cylinders called the cap and the body. The cap fits over the body to form the complete hard shell capsule [42]. The hard-shell capsules utilized in cDPIs are typically prepared from either gelatin or hydroxypropyl methylcellulose (HPMC). Each polymer has unique properties which must be considered in product development (Table 2).

Table 2. Side-by-side comparison between the different capsule materials.

\begin{tabular}{ccc}
\hline \multirow{2}{*}{ Properties } & \multicolumn{2}{c}{ Capsule Material } \\
\cline { 2 - 3 } & Gelatin & HPMC \\
\hline Moisture content & $13-16 \%$ & Less than $9 \%$ \\
Moisture transfer & Hysteretic & Sensitive \\
Required puncture force & More & Less \\
Aperture shape after piercing & Irregular & Regular \\
Shedding of pieces after piercing & More & Less \\
Brittleness & More brittle & Less brittle \\
Generation of "flap" after piercing & More & Less \\
Capsule filling & Easy & Relatively hard \\
Powder retention after inhalation & High & Low \\
FPF after inhalation & High & Low \\
\hline
\end{tabular}

Hard gelatin capsules are made of gelatin and eventually dyes, but do not include any plasticizer. If stored at temperatures between $15-25^{\circ} \mathrm{C}$ and $30-65 \%$ relative humidity $(\mathrm{RH})$, hard gelatin capsule shells will have a moisture content (determined by loss on drying (LOD)) of $13-16 \%$ water due to the hysteresis properties of the gelatin polymer [43]. In these conditions, the capsule can maintain rigidity and elongation [44]; however, if the water content falls below $13 \%$ due to environmental factors (e.g., $<30 \% \mathrm{RH}$ or hygroscopic formulation), the shell will gradually lose its shell flexibility and become brittle [42] On the other hand, if the water content is above $16 \%$, the shells will become soft and sticky [42]. Consequently, alterations in the capsule moisture content may have effects on various aspects including effects on the API-containing powder which may alter the overall product stability and performance. In this regard, it is important to consider that the capsule moisture content is dynamic and directly related to the environmental storage condition with equilibration occurring within hours.

In contrast to hard gelatin capsule shells, HPMC capsule shells typically have a water content of less than $9 \%$ [45] under the standard storage conditions of $15-25^{\circ} \mathrm{C}$ and $30-65 \%$ $\mathrm{RH}$. The differences in water content between gelatin and HPMC capsule materials can affect aerosol performance and lung deposition under certain circumstances. For example, the encapsulation of hygroscopic drugs in hard gelatin capsules may result in increased water loss from the capsule and subsequently changes in the powder properties (e.g., increased agglomeration) as well as brittleness of the capsule [46]. Both may result in reductions in the fine particles fraction (FPF) and deep lung deposition of the drug [23]. In general, HPMC capsule shells seem to be less sensitive to moisture transfer and low water content. Pre-equilibration of both the powder and capsule at the same relative humidity prior to filling can potentially reduce these effects, as discussed in a later section. The selection of the manufacturing process of HPMC capsules (cold-gelling or thermal-gelling) can also affect aerosol performance. Capsules manufactured by cold-gelling use a gelling system (e.g., carrageenan/potassium chloride) leading to a slightly rougher internal capsule surface, while thermal-gelled capsules are composed without a gelling system providing a smooth, glossy surface similar to that of hard gelatin capsules [47]. The importance of the surface roughness of the capsule wall has not been fully studied in inhalation systems. The physical impaction of particles with the rough capsule wall has been shown to increase 
the powder-wall friction by using calcium carbonate and maize starch as experimental drugs [48]. Furthermore, the increased friction can induce uncontrollable powder adhesion to the interior capsule wall [48], which results in the reduction of the emitted dose (ED) [49].

The utilization of gelatin versus HPMC must be carefully considered with regard to some key targets in the QTPP of the cDPI due to the differences in capsule composition and material characteristics. The first gelatin-based capsules used for dry powder inhalers just appeared 50 years ago, which was also the first commercially successful cDPI, whose application was to deliver cromolyn sodium (sodium cromoglycate) by using two pins to puncture the capsules [50]. Until today the evolution of technology and performance of the cDPI systems continues, whereby gelatin capsules are still leading the market due to the ease and availability of capsule filling [51]. Compared to hard gelatin capsules, the recently introduced HPMC capsules have been demonstrated to have several advantages such as requiring less force for shell puncture [52-54] which results in a more regular aperture and less shedding of pieces [55]. This has been correlated to an improved delivered dose, fine particles dose, and less powder retention in the HPMC capsules relative to gelatin capsules [56]. The superior piercing characteristics of HPMC capsules may be related to the reduced brittleness of the shell, particularly when exposed to ambient conditions of less than 30\% RH [57]. Moreover, gelatin capsules were found more susceptible to loss of the shell "flap" created upon piercing by the device $[23,58]$. These "flaps" may be important for the aerosol performance of dry powders since they can potentially change the airflow profile and release from the capsule, as well as that powder could stick to them and not fully get to the patient during inspiration [59]. However, their precise effects on powder de-agglomeration are still poorly understood and require further investigation. To reduce the brittleness of gelatin capsules, $4-6 \%$ of a low molecular weight PEG was added to the gelatin. While the addition slightly reduced the brittleness and improved the piercing, HPMC capsules performed superior in terms of stability and piercing under low moisture conditions [60].

A study from Telko et al. used a statistical experimental design to look specifically at capsule material type effects on powder charging, which is thought to correlate with aerosol performance by affecting powder detachment from surfaces of capsule walls [61]. The authors determined the choice of the capsule (gelatin vs. HPMC) has a large effect on the polarity of the charge but only a minor effect on the magnitude of the charge from the powders. They found the use of HPMC-based capsules led to a higher triboelectric charging of the powder than gelatin-based capsules. However, it has been observed in other studies that a higher potential for triboelectrification was observed in gelatin capsules when compared to HPMC capsules [62], and therefore this effect should be further evaluated and might depend much more on the moisture content of the shells and the formulation itself.

\subsubsection{Capsule Dimension}

Capsule dimensions are based on their respective fill capacities, which in turn are based on the tapped density of the dry powder [63]. Capsule dimension is represented by a numerical size assignment, with larger numerical sizes representing a smaller internal capsule volume that ranges numerically from sizes 000 (the largest size) to 5 (the smallest size) [45]. While capsule size 3 is the standard cDPI capsules, larger and smaller capsule sizes are being evaluated for high-dose drugs or potent APIs. It should be noted that even though the capsule sizes are standardized, capsule dimensions can vary between suppliers. Especially, the close length of the capsule might be important for the piercing performance as well as the movements within the capsule chamber. In this respect, it needs to be assured that the capsules are closed properly and provide sufficient closing strength preventing reopening when pierced at the hemispherical ends. When considering general capsule motion from within a fixed capsule chamber, the smaller capsules may be thought to have more free space and thus can move freely in a turbulent fluid flow. Additionally, there is a long distance for the capsule to travel to impact the chamber walls, which may reduce the number of possible collisions in a given time compared to larger capsules that 
fit more squarely inside the device chamber. This was illustrated in a study performed by Coates et al., in which the overall levels of turbulence within the device were found to diminish with the increase in capsule size [64]. The higher frequency of collisions noted with the larger capsule sizes resulted in increased device powder retention after inhalation. However, while smaller capsules may demonstrate the release of dry powder from the device, this must be balanced with the reduced carrying capacity of the capsule, which may require an increased number of doses loading and inhalation maneuvers by the patient for a therapeutic effect to be achieved.

\subsubsection{Capsule Hardness and Stiffness}

The stiffness and hardness of the capsule can influence the cDPI performance in multiple ways. As described previously, stiffness and hardness alteration of the capsule due to a change in moisture content can affect the capsule piercing characteristics. Harder and stiffer capsule shells require increased puncture force, which may have negative influences on aerosol performance [65]. Additionally, the hardness of the capsule is thought to be a factor that controls the collision velocity between capsules and inhaler walls [53]. When the capsule collides with the inhaler wall with high collision speeds and frequency a considerable impaction force is generated. A capsule with softer shell walls buffers a portion of the impact force, causing the velocity of the capsule motion to decrease. In turn, this leads to a lower collision frequency and alters capsule motion, which further fails to de-aggregate the powder [66] and achieve acceptable powder release [67]. On the other hand, if the capsule is too soft, the high velocity of capsule-inhaler wall collisions can induce macroscale capsule deformation, thus altering the capsule surface from a smooth, flat morphology to a rough morphology and thereby promoting increased powder retention in the capsule [53].

\subsubsection{Others}

The weight ranges of capsules must be narrower for inhalation than standard powder filling due to the low fill weights and potential rejections on the high-speed encapsulators [68]. And the microbial limits on inhalation capsules must be lower due to the drug product inside being delivered directly to the lungs.

Altogether, the capsule-related CMAs lead to the finding that capsule dimension should balance powder payload and aerosol performance, and the moisture contents of the inhalation capsule need to be controlled within a narrow range.

\subsection{CMAs Related cDPIs Device Design}

Powder deaggregation level has been widely proven to be correlated to the design of the cDPI device $[69,70]$. Most marketed cDPIs devices contain four common design features to facilitate powder deaggregation, including grid structure, mouthpiece, capsule chamber, and capsule-opening tool. The following context will discuss these components one by one of their impact on the QTPP performance parameter of cDPIs.

\subsubsection{Grid Structure}

The grids are important for efficient powder deaggregation based upon impaction between the grid and powder during inhalation. The effects of grid design specifically on aerosol performance of cDPIs were examined by Coates et al. [71]. Using computer fluid dynamics (CFD), it could be shown that the grid significantly impacts the flow turbulence levels and particle impaction velocities which triggers the deagglomeration of the DPI powder.

\subsubsection{Mouthpiece Length}

The mouthpiece length has been stated to determine the airflow development inside the mouthpiece and exiting the cDPIs [71]. Ideally, a more developed flow profile at the mouthpiece exit can potentially increase the oropharyngeal deposition of cDPIs after 
actuation. However, from the study given by Coates et al., there is no significant change to FPF if reducing the length of the mouthpiece from the original length to three-quarters and one-half. And minimal difference (6.7 and 6.2\%, respectively vs. $4.9 \%$ ) can be found in the throat impaction among comparison. This conclusion has also been confirmed by Tuteric et al. [72]. They modified the Aerolizer device to different lengths of the mouthpiece and found that higher velocities of flow field were present with mouthpiece length increased. Moreover, they also stated that the modified cDPI which has the longest mouthpiece length exhibited the highest level of deposition.

\subsubsection{Capsule Chamber Design}

In practice, when patients are using a passive cDPI, the inhalation maneuver begins after the capsule has been pierced. In some cases, when the airflow enters the capsule chamber, the capsule moves and may repeatedly collide with the inhaler walls and internal structures [73]. While the amount of research in such capsule motion is limited, a recent study was conducted by Benque et al., which examined capsule rotation in the Aerolizer device using high-speed photography, computational fluid dynamics, and discrete element method (DEM) simulations [74]. The authors found that the amount of capsule rotation produced from different flow rates (between 30 and $100 \mathrm{~L} / \mathrm{min}$ ) was crucial to capsule powder dispersion and that increased capsule collisions vastly improved the discharge of polydisperse powders. Therefore, different capsule chamber designs, which are associated with different capsule motion induction, can also affect the performance of the cDPIs.

Several design iterations of capsule chambers have been featured in a commercially available device, and the differences in these designs have been linked to differences in aerosol performance of cDPIs. For example, the Dinkihaler ${ }^{\circledR}$ (Aventis, GA, USA), the capsule ends are fitted into an impeller-shaped capsule chamber from which powder is released to rotate during inspiration [69]. It spins under the inspirational airflow, and the rotational speed depends on the inspiratory force and breathing cycle which determines the rate of aerosolization and dispersion. In contrast, the Rotahaler ${ }^{\circledR}$ is activated by separating the powder-containing capsule body from the capsule cap into the barrel chamber. During inhalation, powder emission mechanisms from the Rotahaler, regulated by its impaction on the grid and the Rotahaler wall as well as the rotational movement in the entrained air, contributing to the de-agglomeration of the drug powder [75]. Chew and colleagues compared these two devices with different capsule chamber designs and found that Dinkihaler ${ }^{\circledR}$ DPI gave much higher FPF [69].

Different capsule chamber designs can also determine the capsule position once loaded into the capsule cavity, which may further affect the performance of the cDPIs. The study given by Behara et al., compared two different experimental capsule device chamber designs, in which the long axis of the capsule has oriented either perpendicular or aligned with the airflow passage. The perpendicular design was found to increase the vibrational frequency of the capsule compared with capsules aligned with the flow, which increased the deaggregation of the dry powder and resulted in a smaller MMAD, but more powder retention in the capsule [76]. Recently, the vertical aerosolization chamber design along with the aforementioned 3D array design has been reported to be applied in a positive pressure cDPI for children, which showed advantageous lung delivery efficiency [77]. Moreover, whether the angle between the capsule chamber and the flow passage affects aerosol performance has also been studied. In another study given by Behara et al., they compared inhalers that implement either a $45^{\circ}$ or $90^{\circ}$ angle designed cDPIs [78]. However, no significant differences have been discovered regarding aerosol performance.

As the example of commercialized cDPI devices, the long axis of Cyclohaler ${ }^{\circledR}$ (with a similar design to the Aerolizer ${ }^{\circledR}$ in the USA) is aligned with the tangential direction, while HandiHaler ${ }^{\circledR}$ is different which enable capsule to be inserted in the vertical position, and rest over the chamber inlet. Shur et al., examined pressure and velocity distributions in the capsule chamber of the HandiHaler ${ }^{\circledR}$ and Cyclohaler ${ }^{\circledR}$. This supplied a near comprehensive view of the capsule motion inside these two inhalers respectively [73]. For the HandiHaler ${ }^{\circledR}$, 
the sequential high-speed video images revealed the axial vibration movement sustained throughout the operation of the device, which impels the powder to exit the capsule. Conversely, due to the distinguished structure of Cyclohaler ${ }^{\circledR}$, swirling or cyclonic flow structure dominated the flow pattern inside the Cyclohaler $^{\circledR}$, which resulted in the capsule moving across a rotational axis thus forcing the capsule rotation [73]. Consequently, while they have a comparable median mass aerodynamic diameter (MMAD), ED of the tested dry power obtained by Cyclohaler ${ }^{\circledR}$ is $14 \%$ and $15 \%$ less compared to HandiHaler ${ }^{\circledR}$ at 20 and $39 \mathrm{~L} / \mathrm{min}$ air flow rate, respectively [73].

\subsubsection{Capsule-Opening Mechanisms}

Several capsule-opening tool designs have been developed to facilitate capsule opening and powder release, including piercing the capsule shell with sharpened pins, shear opening, or cutting it with blades [51,55]. In this review, only the pin-based capsule open mechanism will be discussed due to the availability of published data on these designs. For pin-based capsule activation devices, four identified stages make up the puncturing event (Figure 3). Stage 1 is the initial interaction of the pin and the capsule, with the rapidly increasing piercing force and deformation of the capsule. Stage 2 involves the puncturing of the capsule shell resulting in a sharp reduction of the pin forces. Stage 3, in which the pin keeps penetrating through the shell, is characterized by the progressive reduction in the puncturing force. At this stage, the resistance to the piercing mostly comes from the frictional forces between the surface of the pin and the outside edge of the punctured aperture in the capsule, including any flaps. Finally, Stage 4 is the removal of the pin from the capsule [53].

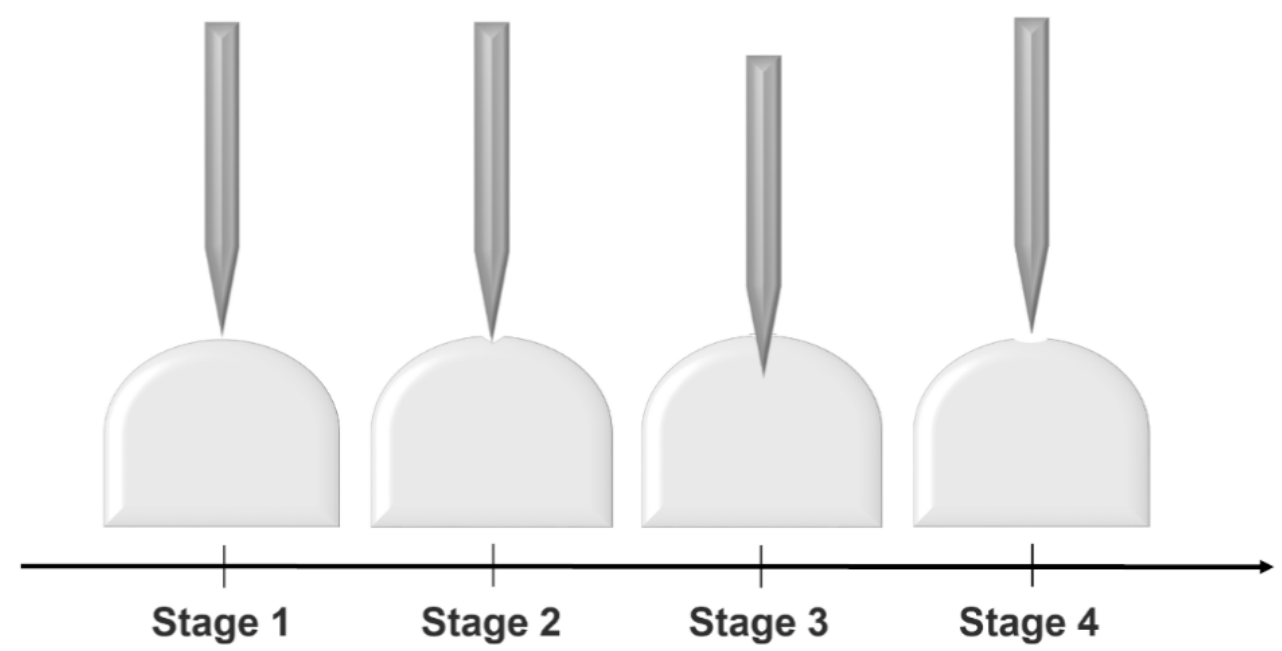

Figure 3. Puncturing process of the capsule. Stage 1: the initial interaction of the pin and the capsule. Stage 2: the pin expose forces to the intact capsule shell. Stage 3: the pin punctures the capsule shell and keeps entering. Stage 4: the pin is removed from the pierced capsule.

Capsule opening is crucial to the successful delivery of the powder from the capsule, since capsule piercing characteristics associated with aperture (aperture shape, size, orientation, number) can affect the emitting manner of dry powder inside the capsule substantially. In addition, the orifices of capsules can also change the nature of the airflow dynamics, in manners such as altering the turbulence inside as well as outside the capsule. This affects the capsule motion in the device and the release and/or retention of powder in the capsules [76,79]. Therefore, discussion on distinctive piercing characteristics caused by differences in pin (number, orientation, size, shape) has been widely studied.

\section{Pin Number}

Saleem et al., looked at the influence of pin number by using DPIs (with a different number of punctures (2-pins vs. 8-pins) [80]. A significant difference was found using 
HPMC capsules between 8-pin and 2-pin DPI devices, demonstrating that the 2-pin DPI device showed significantly lower MMAD in comparison with the 8-pin DPI device Another study conducted by Torrisi et al., looked at the number of punctures ( 2 sets of 4-pins vs. 2 single pins DPI) with gelatin and HPMC capsules, indicating that a greater mean force was needed for 2 sets of 4-pins penetration in Stage 1 and Stage 2 puncturing event mentioned before in both HPMC and gelatin capsules compared to single pin penetration [53].

\section{Pin Orientation}

Behara et al., conducted the experiments for the assessment of the effect of pin orientation by where a custom capsule jig was used to create a capsule with different aperture orientations. They compared five different cases of capsule aperture orientations (Case 1: the start of top curvature as air inlet aperture and the start of bottom curvature as air outlet aperture; Case 2: the start of top curvature as air inlet aperture and the middle of bottom curvature as air outlet aperture; Case 3: the start of top curvature as air inlet aperture and the center of the bottom dome as air outlet aperture; Case 4: the middle of top curvature as air inlet aperture and the middle of bottom curvature as air outlet aperture; Case 5: the center of the top dome as air inlet aperture and the middle of bottom curvature as air outlet aperture) [78] (Figure 4). As a result, although capsules with Case 1 aperture orientation showed the most capsule powder retention proportion and the smallest capsule inhaler retention proportion, no significant difference was found on ED or other inhalation metrics among capsules with Case 1 to Case 3 aperture orientation. This suggests that the air outlet aperture orientation has little importance to the device's performance. Another comparison between capsules with Case 2, Case 4, and Case 5 aperture orientation showed that capsules with Case 2 aperture orientation exhibited better aerosol performance, indicating that the start of top curvature's air inlet aperture probably is the most optimal strategy for inhalation. Interestingly, Shur et al., reported a similar result. They found that the air inlet orifice of the capsule can produce a high-velocity air jet through the CFD model of the HandiHaler ${ }^{\circledR}$ [73]. The authors concluded that the location of the air inlet aperture of the capsule, which is associated with pin orientations, was of great significance for optimal fluid flow.

\section{Pin Size}

Pin size can decide the capsule pierced orifice size after actuation. Capsule orifice size may be linked with powder residence time within the capsule depending on the device, formulation, and inhalation effort, and may facilitate powder de-agglomeration as well as powder emptying [64]. Son et al., compared the energy available for the powder dispersions $\left(E_{\text {dispersion }}\right)$ and powder dispersion characteristics of two $1.5 \mathrm{~mm}$ orifice versus a $0.5 \mathrm{~mm}$ orifice created by HandiHaler ${ }^{\circledR}$ needles, showing that, though the capsule with $0.5 \mathrm{~mm}$ pierced aperture required more $\mathrm{E}_{\text {dispersion, }}$ it had a larger FPF less than $5 \mu \mathrm{m}$ in diameter (FPF $<5 \mu \mathrm{m}$ ), while having a lower MMAD and ED [81]. This indicates that the optimized aperture size is likely to be in a range that allows for both sufficient de-agglomeration of powder and minimizes powder retention. With a large aperture, agglomerates will easily emit from the capsule but will result in large particles sizes at the same time. However, significant powder retention can be caused by an aperture that is too small [82]. For different cDPIs, this optimal size range can be quite diverse. For the Dinkihaler ${ }^{\circledR}$, the optimal orifice size of the capsule range was found to be 1.00 and $2.38 \mathrm{~mm}$, with the favorable FPF $<5 \mu \mathrm{m}$ of $50-60 \%$ by mass with significantly less capsule and device powder retention [83]. Another study given by Behara et al., suggested that the size of the capsule aperture should be around $0.5 \mathrm{~mm}$. This was done by comparing three different aperture sizes of $1.5,0.8$, and $0.5 \mathrm{~mm}$ punctured by HandiHaler ${ }^{\circledR}$ needles in order to maximize FPF but minimize the MMAD [76]. Behara et al., also had another independent study that accurately calculated the de-agglomeration rate $\left(k_{d}\right)$ and found that a decrease in capsule aperture size increased the $k_{d}$ [84]. Therefore, optimal capsule aperture size should 
be a range, instead of a definite number and will vary between the different inhaler devices in order to meet both the satisfied aerosol performance and minimized powder retention.

(a) Piercing Jig

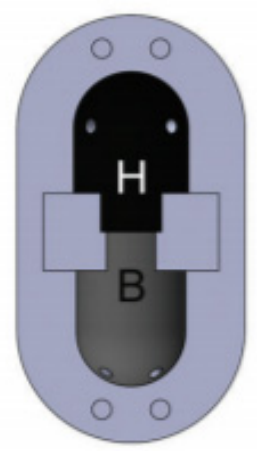

(d) Case 3

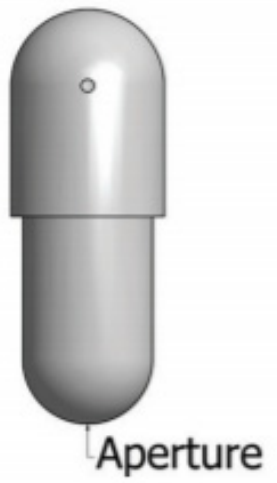

(b) Case 1

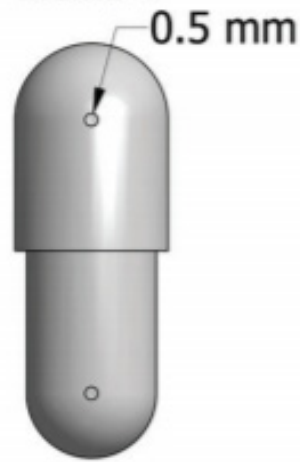

(e) Case 4

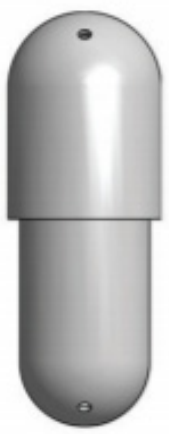

(c) Case 2

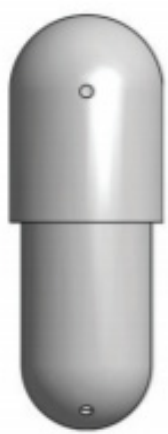

(f) Case 5

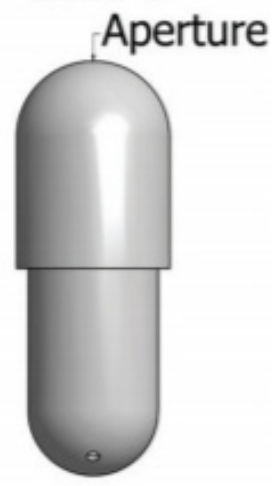

Figure 4. Five different cases of capsule aperture orientations generated by capsule jig piercing at different orientations. Reproduced with permission from [78], Elsevier, 2014.

\section{Pin Shape}

There are few studies about the effect of pin shape, one representative example is given by Torrisi et al. [53]. In their study, a conical pin, which was described as a decreasing diameter rod ending in a rounded pin tip, and an angular pin, which showed as a flattened structure ending in a point, have been used for comparison. As a result, differences have been investigated within both Stage 2 and Stage 3 puncturing events. At the terminal point of Stage 2, interestingly, the recorded force for angular pin puncture did not reduce to $0 \mathrm{~N}$, as the conical pin did, indicating that angular pin puncture causes the formation of flap attached to the capsule walls [53]. The reason might be the structural differences between these two pins. The rounded pin tip of the conical pin was suitable for puncturing the shell wall, while the beveled pin tip tended to cut the capsule shell wall like a blade to penetrate. The recorded forces and force duration of Stage 3 were found to be greater for the angular pin in comparison to the conical pin, which is attributed to the longer tapered portion of the angular pin. These pin shape-induced puncture profiles differences resulted in aperture shape and flap attachment differences. While from the investigation of this study, angular pin tended to form irregular aperture shape and cause flap retention after piercing [53]. Having capsules with irregular apertures increases the possibility of causing the cracked or fractured capsules pieces, which further increase the aperture structure and size to affecting the performance criteria of cDPIs as mentioned above.

In all, the capsule-opening mechanism as described for the pin-based capsule activation devices, reveal a complex interaction between the pin design, capsule attributes, and 
device factors which finally require investigation and eventually optimization of pin shape, number, orientation, and size for each product (Figure 5).

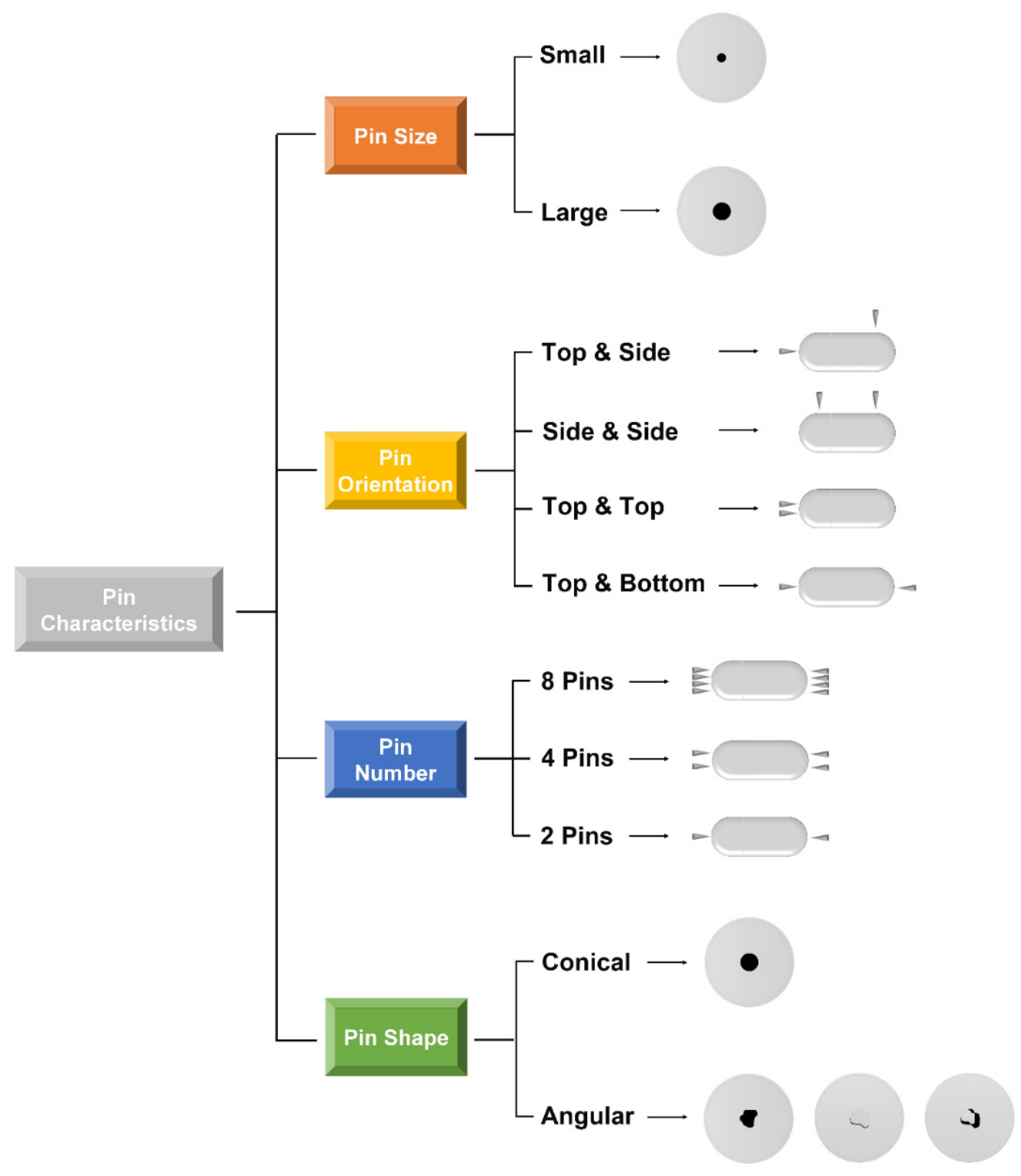

Figure 5. The pin characteristics category within pin activated cDPIs and their outcome on capsule appearance after piercing.

\subsection{Dry Powder Related CMAs}

A key CQA of the CDPI product defined in the QTPP is the reproducible, targeted delivery to the lung under patient acceptable use patterns. Taking this into account, efficient delivery to the lungs requires that the inhaled dry powder should be able to bypass deposition in the upper respiratory tract, and not being exhaled when used by the patients e.g., with impaired lung functions [85].

The aerodynamic diameter $\left(d_{a e}\right)$ of the API or API loaded particles has been found to determine the in vivo deposition of a cDPI product [86]. It was shown that the percentage of the dry powder with $d_{a e}<3 \mu \mathrm{m}$ have a closer numerical equivalence to the in vivo lung deposition [86]. However, neat dry powders $\left(d_{a e}<3 \mu \mathrm{m}\right)$ are prone to agglomerate due to the interparticulate cohesive and adhesive forces and high surface energy [87]. Since the inspiratory flow rate plays a key role in powder deagglomeration, the physicochemical properties of the API particles or the API containing dry powder mixtures are most important for targeted lung delivery [85]. At fixed inspiratory flow rates (e.g., 30, 60, 
$90 \mathrm{~L} / \mathrm{min}$ ), the evaluation of the physicochemical properties of the dry powder provides a necessary CQA since it is associated with the de-agglomeration of the powder within the capsule during inhalation. To enhance processing and powder de-agglomeration within cDPI during inhalation, most dry powder mixtures use coarser carrier excipients, mainly lactose [88]. The drug particles in such powder mixtures adhere to the surface of the lactose particle during blending, which allows for better-flowing powders and more uniform dispersions. These carrier-based formulations transform cohesive agglomerates of drug particles in drug-carrier adhesive agglomerates. In this case, in addition to dry powder, the physicochemical properties of sugar carriers (mostly lactose) must be considered and investigated as a CMA.

\subsubsection{Carrier-Free Systems}

Pertaining to the carrier-free systems, the $d_{a e}$ of the API powder exits from the cDPIs should be at around 1-3 $\mu \mathrm{m}$ for deep lung deposition. The $d_{a e}$ of the API particles is determined by its using equation if regardless of the effect of inspiratory flow rate [89]:

$$
d_{a e}=d_{g e o} \sqrt{ }\left(\frac{\rho_{p}}{\rho_{o} X}\right),
$$

where $d_{\text {geo }}$ represents the geometric diameter of the API particle, $X$ is the dynamic shape factor (e.g., deviation from API particle sphericity), $\rho_{p}$ and $\rho_{o}$ are the API particle and unit densities, respectively. From the equation, the geometric size [90] and density [91] of the API particles can result in significant changes in performance. For example, high porosity (low density) API particles do tend to distribute in deeper pulmonary tissue [92]. And one study from Brunaugh et al., found that decreasing the size of clofazimine by jet milling can significantly increase the aerosol performance of this excipient-free formulation [93]. More detailed information about other factors can be found in Table 3.

The interparticle interactions of pure API-associated powder are characterized by higher surface energy which are important factors for the physicochemical properties [94] besides a decreased particle volume and geometric diameter of the API particle. In this case, the powder deaggregation mechanism illustrated in Figure 6a upon aerosolization is of great importance to break the powder agglomerates and release the API fines. Studies have indicated that collisions between the agglomerates and the capsule in the flow field are conducive to the breakage of agglomerates [95]. Factors like impact velocity [96] and impact angle $[97,98]$ are other factors that affect agglomerated powder facture tremendously.

a)

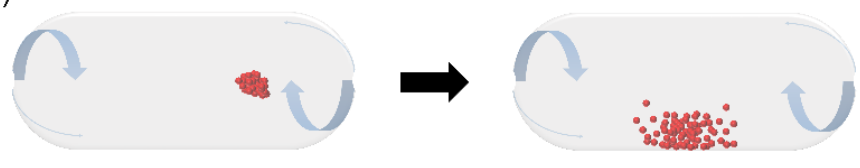

b)

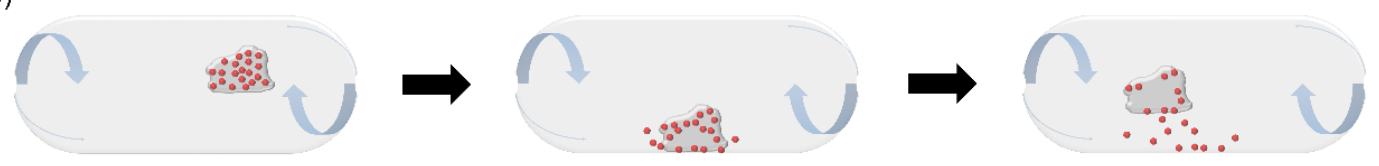

Figure 6. Schematic illustration of de-agglomeration mechanism within the capsule for (a) carrier-free agglomerates and (b) carrier-based formulation. 
Table 3. Summary of dry powder-related CMAs and their influence on CQAs and QTPP of cDPIs.

\begin{tabular}{|c|c|c|c|c|}
\hline $\begin{array}{c}\text { Dry Powder Related } \\
\text { CMAs }\end{array}$ & CQAs & QTPP & Comments & References \\
\hline API particle morphology & $\begin{array}{c}\text { Powder dispersion and } \\
\text { de-aggregation }\end{array}$ & $\begin{array}{l}\text { Target drug effects in } \\
\text { deep lung }\end{array}$ & $\begin{array}{l}\text { Higher porosity of the API particles } \\
\text { gives more lung deposition }\end{array}$ & [99] \\
\hline API particle size & $\begin{array}{l}\text { Powder dispersion and } \\
\text { de-aggregation }\end{array}$ & $\begin{array}{l}\text { Target drug effects in } \\
\text { deep lung }\end{array}$ & $\begin{array}{l}\text { Smaller size API particles gives more } \\
\text { lung deposition }\end{array}$ & {$[90,93]$} \\
\hline API particle density & $\begin{array}{c}\text { Powder dispersion and } \\
\text { de-aggregation }\end{array}$ & $\begin{array}{l}\text { Target drug effects in } \\
\text { deep lung }\end{array}$ & $\begin{array}{l}\text { API particles with lower density } \\
\text { gives more lung deposition }\end{array}$ & {$[91]$} \\
\hline $\begin{array}{l}\text { API/carrier } \\
\text { hygroscopicity }\end{array}$ & $\begin{array}{c}\text { Powder dispersion, } \\
\text { de-aggregation, and } \\
\text { detachment from carriers }\end{array}$ & $\begin{array}{l}\text { Target drug effects in } \\
\text { deep lung }\end{array}$ & $\begin{array}{l}\text { Particle interactions may be } \\
\text { dominated by the action of capillary } \\
\text { forces in powder systems if humidity } \\
\text { has surpassed critical levels }\end{array}$ & {$[100]$} \\
\hline $\begin{array}{l}\text { API particle electrostatic } \\
\text { charging }\end{array}$ & $\begin{array}{l}\text { Powder dispersion and } \\
\text { de-aggregation }\end{array}$ & $\begin{array}{l}\text { Target drug effects in } \\
\text { deep lung }\end{array}$ & $\begin{array}{l}\text { API particles with lower charge } \\
\text { gives more lung deposition }\end{array}$ & [49] \\
\hline API stability & $\begin{array}{l}\text { Effective dose } \\
\text { delivery }\end{array}$ & $\begin{array}{l}\text { Ensuring therapeutic } \\
\text { effect, avoiding side } \\
\text { effects }\end{array}$ & $\begin{array}{l}\text { API particles with better stability } \\
\text { gives more effective dose delivery }\end{array}$ & {$[101]$} \\
\hline API impurity & $\begin{array}{l}\text { Effective dose } \\
\text { delivery }\end{array}$ & $\begin{array}{l}\text { Ensuring therapeutic } \\
\text { effect and avoiding side } \\
\text { effects }\end{array}$ & $\begin{array}{l}\text { API particles with less impurity } \\
\text { gives more effective dose delivery }\end{array}$ & {$[102]$} \\
\hline $\begin{array}{l}\text { API/carrier surface } \\
\text { roughness/rugosity }\end{array}$ & $\begin{array}{l}\text { API dispersion and } \\
\text { detachment }\end{array}$ & $\begin{array}{l}\text { Target drug effects in } \\
\text { deep lung }\end{array}$ & $\begin{array}{l}\text { API particles with rougher gives } \\
\text { more lung deposition; the decrease } \\
\text { of the surface roughness of lactose } \\
\text { carrier particles in terbutaline sulfate } \\
\text { delivery case gives more lung } \\
\text { deposition }\end{array}$ & [103-105] \\
\hline $\begin{array}{l}\text { Carrier electrostatic } \\
\text { charging }\end{array}$ & $\begin{array}{l}\text { API dispersion and } \\
\text { detachment }\end{array}$ & $\begin{array}{l}\text { Target drug effects in } \\
\text { deep lung }\end{array}$ & $\begin{array}{l}\text { API particles with lower charge } \\
\text { gives more lung deposition }\end{array}$ & {$[49]$} \\
\hline Carrier particle shape & $\begin{array}{l}\text { API dispersion and } \\
\text { detachment }\end{array}$ & $\begin{array}{l}\text { Target drug effects in } \\
\text { deep lung }\end{array}$ & $\begin{array}{l}\text { The values of either the surface } \\
\text { factor or the elongation ratio of } \\
\text { lactose in direct proportion to the } \\
\text { dispersibility of salbutamol sulfate }\end{array}$ & {$[106]$} \\
\hline $\begin{array}{c}\text { Carrier } \\
\text { crystallinity/polymorphs }\end{array}$ & $\begin{array}{l}\text { API dispersion and } \\
\text { detachment }\end{array}$ & $\begin{array}{l}\text { Target drug effects in } \\
\text { deep lung }\end{array}$ & $\begin{array}{c}\alpha \text {-lactose monohydrate has better } \\
\text { performance than anhydrous } \\
\beta \text {-lactose }\end{array}$ & {$[107]$} \\
\hline Carrier impurity & $\begin{array}{l}\text { API dispersion and } \\
\text { detachment }\end{array}$ & $\begin{array}{l}\text { Target drug effects in } \\
\text { deep lung }\end{array}$ & $\begin{array}{l}\text { Impurities may be responsible for an } \\
\text { increase in the adhesive forces } \\
\text { between drug and carrier particles }\end{array}$ & {$[108]$} \\
\hline Carrier particle size & $\begin{array}{l}\text { API dispersion and } \\
\text { detachment }\end{array}$ & $\begin{array}{l}\text { Target drug effects in } \\
\text { deep lung }\end{array}$ & $\begin{array}{l}\text { Reduction of carrier particle size has } \\
\text { been proved to ameliorate the } \\
\text { aerosolization of various drugs. } \\
\text { However, the too-small carrier can } \\
\text { also lead to poor flow properties in } \\
\text { the powder due to stronger charging } \\
\text { interactions caused by increased } \\
\text { surface area }\end{array}$ & {$[70,109,110]$} \\
\hline
\end{tabular}

\subsubsection{Carrier-Based Systems}

In order to facilitate the API de-agglomeration and release carrier-based formulation systems are used [111]. When it comes to the carrier-based formulation systems, the capsule-derived dispersion of the drug-carrier system is linked with drug-capsule wall collisions, turbulence [112], shear stress during turbulence [113], as well as impactions of particle-particle collisions [13]. Especially the wall collision is an important step for drug detachment from the coarser carrier due to higher kinetic energy during aerosolization [114] (Figure 6b). Usually, the drug-carrier adhesive force contains a combination of forces such as the van der Waals forces (the most substantial forces), electrostatic forces, interlocking forces, and capillary forces [115]. Chemical forces like hydrogen bonding and acid-base interaction forces have also been reported [116]. Considering the effect of carrier particle- 
wall impaction on dry powder detachment from the carrier, the determination of the detachment efficiency is evaluated by the balance of adhesion energy and impact energy. Therefore, a primary factor related to powder physicochemical property is the adhesion energy of the dry powder, which is inversely proportional to dry powder detachment. Less the contact area between the micronized drug powder and carrier (e.g., increased roughness of dry powder particles, lower specific surface area), the decreased surface energy of the contiguous surfaces, and lower electrostatic charges of dry powder particles, contribute to the reduction of the adhesion force or energy [117].

Furthermore, in addition to dry powder detachment, there is a re-attachment mechanism when the carrier itself collides with the capsule wall that adhered to dry powder fines from a previous collision [118]. Taking all into consideration, physicochemical properties (e.g., polymorphic form, size, etc.) of the carrier excipient are CMA that need to be considered in the same way as the CMA of the API as they are critical for the reproducible performance of a cDPI as defined in the QTPP (Table 3). Though the types of carrier excipients have been thought to affect the charge deposition for dry powder [110], the most commonly used carrier excipient is lactose, thereby only lactose will be discussed in this section. Lactose for inhalation purposes is available in multiple grades, particle size/size distribution, shapes, and surface properties. The selection of the lactose carrier depends on the API particle properties and should be carefully investigated during the formulation development.

In all, the dry powder related CMAs lead to the finding that in the carrier-free formulation, dry powder with required physicochemical properties (e.g., small size, low density, high roughness, low specific surface area, low electrostatic charges, and relatively aspherical shape) are thought to be important determinants for deep lung deposition. With the introduction of carrier-based formulation into dry powder delivery, the selection of the carrier excipients (e.g., lactose) requires careful investigation regarding their physicochemical properties (proper size range, crystalline form, relatively spherical shape, high smoothness) to guarantee QTPP/CQAs achievement.

\section{Critical Process Parameters (CPPs) in cDPIs}

Process understanding through the identification of influential input operating parameters that potentially impact CQAs is a critical part of the pharmaceutical development process. The assessed variables with criticality are CPPs. Based upon the CMAs identified above in cDPIs, CPPs associated with the CQAs of cDPIs are capsule processing and formulation processing.

\subsection{Capsule Manufacturing}

To manufacture gelatin hard capsules for use in DPIs, the first step is to prepare a gelatin solution in demineralized water at a temperature between 60 and $70{ }^{\circ} \mathrm{C}$, which is sufficient to dissolve gelatin and prevent microbial growth [119]. A $30-40 \% w / w$ gelatin solution is viscous and thus is prepared under vacuum to prevent the formation of bubbles. At this step in the process, colorants, and other processing aids (e.g., sodium lauryl sulfate to reduce surface tension) may be added. Viscosity is a critical parameter for determining the capsule wall thickness, which can potentially affect some CQAs by changing the hardness or piercing performance of the capsule. The gelatin solution is fed continuously into the dipping dishes, and standardized steel pins in rows are dipped into the temperaturecontrolled solution at a predetermined depth. The dipping process is designed so the caps and bodies of the capsules are produced simultaneously. After dipping, the bars are rotated to facilitate even distribution of the gelatin solution around the steel pins, and then the pins undergo several drying stages to achieve the target moisture content [42]. The caps and bodies are then stripped from the pins and trimmed to the appropriate length before being joined together [63]. The process can be visualized in Figure 7. 


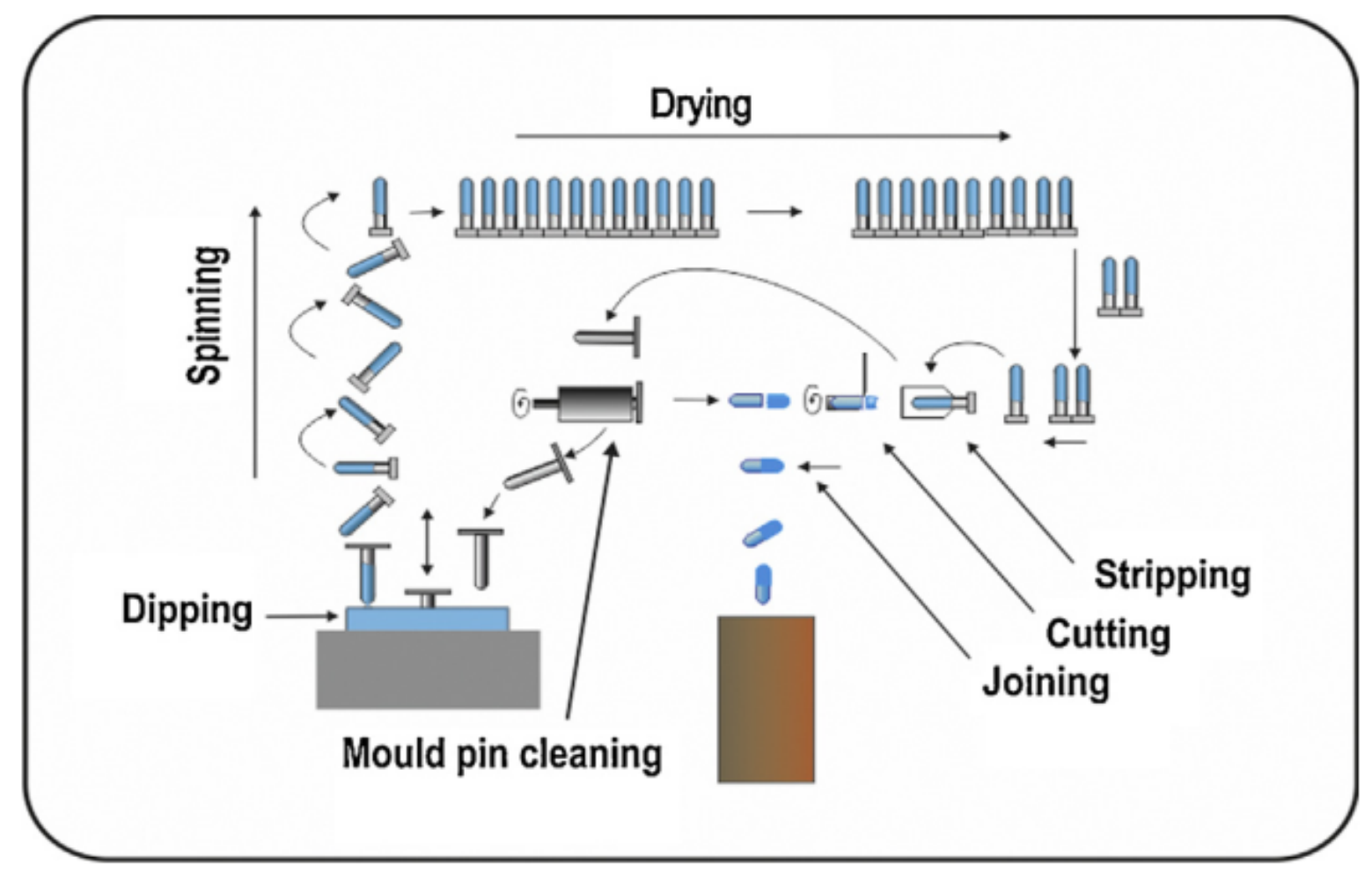

Figure 7. Hard capsule manufacturing. Reproduced with the permission from [120], Elsevier, 2016.

The manufacturing process of the HPMC capsule containing a gelling system is similar to that of gelatin capsules following the method developed by Eli Lilly, but other methods have been developed [121]. Unlike gelatin solutions, HPMC, gelling system solutions must be of higher temperature $\left(70^{\circ} \mathrm{C}\right)$ to form a film. Due to the poor film formation of HPMC solutions, the success of the manufacturing process of HPMC capsule shells is essential to have a gelling agent (e.g., carrageenan, Pectin, and glycerin, gellan gum) if using the conventional dip molding process similar to hard gelatin capsule shells [122]. Carrageenan is a family of linear sulfated polysaccharides extracted from red edible seaweeds, which can interact with two molecular chains of HPMC in a three-dimensional to form a double helix structure giving a high gel strength to capsules if the auxiliary for gelation contains potassium ion [123]. Specifically, Shionogi Qualicaps Co. (Osaka, Japan) and Zhejiang LinFeng Capsules Co. Ltd. (Shaoxing, China) applied this method and developed their market product Quali-V ${ }^{\circledR}$ HPMC capsules and VegiCaps ${ }^{\circledR}$ Natural Plant Capsule HPMC capsules, respectively. Gellan gum is a water-soluble anionic polysaccharide generated by the bacterium Sphingomonas elodea, which can produce the HPMC capsule together with sodium citrate or ethylenediamine tetra acetic acid as a gelling promotor [124]. Vcaps ${ }^{\circledR}$ HPMC capsules from Capsugel (now is Lonza Company, Basel, Switzerland) are manufactured based on this gelling aid. Pectin and glycerin used for gelling with the presence of glacial acetic acid, calcium gluconate, as well as sucrose fatty acid ester are patented by Suheung Capsule Co., Ltd. which later is utilized to produce Embo Caps-Vg ${ }^{\circledR} \mathrm{HPMC}$ capsules [125] (Table 4). 
Table 4. Information on the empty HPMC capsules and their manufacturer, reprinted from [126], Canadian Society for Pharmaceutical Sciences 2010.

\begin{tabular}{|c|c|c|c|}
\hline Capsule Shell Brand & Name Manufacturer & $\begin{array}{l}\text { Registered Year } \\
\text { in the U.S. }\end{array}$ & Gelling Aid \\
\hline Quali-V & Shionogi Qualicaps & July 2002 & Carrageenan \\
\hline Vcaps Plus & $\begin{array}{c}\text { Capsugel (A division of } \\
\text { Pfizer) }\end{array}$ & - & None \\
\hline Vcaps & $\begin{array}{c}\text { Capsugel (A division of } \\
\text { Pfizer) }\end{array}$ & April 2003 & Gellan gum \\
\hline VegiCaps & $\begin{array}{c}\text { G S Technologies Inc. (now } \\
\text { R.P. Scherer Technologies } \\
\text { ownership) }\end{array}$ & May 1989 & None \\
\hline Embo Caps -Vg & Suheung Capsule Co., Ltd. & - & Pectin and glycerin \\
\hline $\begin{array}{c}\text { Capstech's HPMC } \\
\text { Capsule }\end{array}$ & Baotou Capstech Co., Ltd. & - & None \\
\hline $\begin{array}{l}\text { Natural Plant } \\
\text { Capsule }\end{array}$ & $\begin{array}{l}\text { Zhejiang LinFeng Capsules } \\
\text { Co. Ltd. }\end{array}$ & - & Carrageenan \\
\hline
\end{tabular}

A second approach used to manufacture HPMC capsules does not require a gelling system. Rather, the process occurs by dipping hot steel pins into room temperature HPMC solution (i.e., the opposite of cold-gelling, where cold steel pins are dipped into hot HPMC solution) [47]. Different from gelatin, which is liquid at high temperatures and gels when passed through a lower temperature [127], HPMC solutions undergo a sol-gel transformation at a temperature specific to the type of HPMC used [128]. This process of using hot steel pins dipping into HPMC solution at room temperature is known as thermal-gelling [129].

A study including four different capsule formulations' impact on salbutamol was performed across a stability program [130]. Seven distinct factors were measured which all contribute to the effectiveness of the formulation delivery. The results showed a capsule shell formulation of HPMC that included a gelling agent (carrageenan) and an additional plasticizer (PEG-3350) performed better than other more standard capsule shells with regards to FPF and drug powder retention [130]. Therefore, any variables within HPMC capsules manufacturing must be considered as CMA due to a potential effect on CQAs of the cDPIs.

\subsection{Capsule Coating Involvement}

The final step in manufacturing the hard shell capsules is the removal of the caps and bodies from the steel pins after drying $[63,119]$. To facilitate this process and ensure the capsule pieces easily slide off, the steel pins are coated on the interior surface with a surface lubricant to function as a release aid $[51,120]$. The amount of lubricant utilized in the process was not considered to alter the aerosolization properties of powders from cDPIs [80]. The findings from Saim and Horhota determined lubricant levels affect drug retention in the gelatin capsule. The authors hypothesized the effect was related to surface heterogeneity on the internal surface of the gelatin capsule, and there was a range where the lubricant thickness was small enough for particles to become entrapped within the irregular surface [51]. Diez et al., tested salbutamol sulfate $(200 \mathrm{mcg})$, salmeterol xinafoate/fluticasone propionate $(100 / 200 \mathrm{mcg})$, and budesonide/formoterol fumarate $(400 / 6 \mathrm{mcg})$ with four internal lubricant variations on the pin bars during HPMC capsule manufacturing [131]. FPD was measured at ambient conditions and after an accelerated stability protocol. Differences were noticed in the aerosolization results which indicate the four internal lubricant levels of the inhalation capsules for certain formulations could be customized to optimize performance for emitted dose, fine particle fraction, and mass media aerodynamic diameter [131]. Saleem et al., suggested that there should be an optimal 
range of surface lubricant to achieve good powder release from HPMC capsules (measured by drug deposition, ED, and FPF) [80]. The authors also proposed this effect was related to the internal capsule surface homogeneity, where higher lubricant levels led to a smoother internal surface and better aerosolization, since the internal surface lubricant content could potentially be purposely altered to influence capsule-based DPI powder characteristics, as well as abating the electrostatic forces between the capsule and dry powder [132]. Besides the inner lubricant level, the moisture content of the capsule is an important factor responsible for powder retention. It was found that a lower lubricant content reduces powder retention, while low capsule moisture leads to higher powder retention inside the capsule [133].

Differently, Desmond et al., coated the interior surface of the capsule with magnesium stearate (MgSt), which can form stronger Langmuir type films on surfaces potentially sequester the direct contact between formulation powder and capsule [134-137]. They used two capsule-based DPIs, the Rotahaler ${ }^{\circledR}$, and the Aerolizer ${ }^{\circledR}$, and found that the retained powder in the capsule largely decreased with a concentration of $0.3 \mathrm{~g} / \mathrm{mL} \mathrm{MgSt}$ in Aerolizer ${ }^{\circledR}$ and $0.05 \mathrm{~g} / \mathrm{mL}$ in Rotahaler $^{\circledR}$ [49]. The enhancement effect on powder emptying was also verified by Srinivas et al., who found that capsules coated with MgSt had a decrease in capsule drug retention compared to uncoated [76]. Interestingly, the same effect was found if using excipient enhanced growth (EEG) $[138,139]$ particles or L-leucine, indicating that any substance with a lubricant nature may reduce capsule retention [76]. Lastly, it was thought theoretically that the particle size distribution of the lubricant used in carrier-based formulations would affect detachment and de-agglomeration and cause fluctuations in capsule retention, however, this did not show in the experiment [76].

In addition to interior coating, capsule exterior coating is another distinctive capsule coating strategy, which reduces the electrostatic forces between capsule and DPI. One representative study by Srinivas et al., exhibited that coating the exterior surface of the capsule and the interior surface of the inhaler with the same commercial polytetrafluoroethylene (PTFE) suspension (LUTM708, Sprayon Products, Cleveland, OH, USA) can dramatically decrease the drug retention of the capsule, inhaler as well as the mouthpiece. While the detailed mechanism remains unknown [76], PTFE is a special material with low surface energy (high contact angle) with notorious non-stick properties as well. Whether or not other coating materials can also function in the same manner is yet to be explored.

\subsection{Capsule Filling Control}

\subsubsection{Filling Method}

Dry powder must be metered into a capsule to allow application of the product by an inhalation device. On a laboratory scale, a capsule is usually filled manually. For clinical and commercial purposes, specialized dosing equipment is required for capsule filling due to the low fill weights in each dose. Dosator technology is the most traditional automated filling system, which consists of mechanical compaction-based dosator systems and vacuum compaction-based dosator systems $[10,140]$. The compaction of powder leads to the increase of bulk density of the powder, which highly affects powder flowability [141], serving as the disadvantage of traditional dosator systems. Recently microdosing dosator filling has been developed which does not require compaction. A study by Faulhammer et al., investigated the CPP of the microdosing comparing the performance of different types of powders. The study provided evidence that the accurate filling of $1-45 \mathrm{mg}$ of DPI powders into capsules depends on processing parameters that can be adjusted for the different types of powders [142]. Different from dosator systems, tamp filling system is an automated filling system requiring a lower degree of formulation compaction, and is very suitable for loading highly potent compounds [143]. A more recent capsule dosing technology is based on 'pepper-shaker' or 'pepper-pot' principle [144]. This method fills the capsule by tapping the powder in a pepper-shaped shaker or pot, without the consolidation of powder to transfer the powder to the capsule. Importantly, it can precisely fill the capsule with a dose as low as $10 \mu \mathrm{g}$, which is perfect for the expensive or potent 
drug [10]. An additional benefit can be its ability to be fitted with a relative humidity control unit, thus decreasing aggregates formation when the ambient humidity is too high [10]. However, the limitation of this technology is the limited throughput which is limited to 600 capsules/h [145].

\subsubsection{Filling Weight Variability}

For automated machine filling, powder flowability is a critical factor to achieve consistent fill weight [146]. Faulhammer et al. conducted a comprehensive DoEs study to understand process parameters involved in dosator capsule filling process that influence filling weight variability [147]. In their study, different conclusions can be obtained on the correlation between filling weight variability and capsule filling method parameters with the use of powder of different properties. Large particles with high density exhibited an inverse correlation between filling weight variability and capsule filling method parameters (the dosator diameter, filling speed, and the powder layer depth). While for low dense particles with a particle size less than $10 \mu \mathrm{m}$, high filling speed resulted in high filling weight variability. In an additional study, they found a correlation between the capsule filling weight and the particle size, the air permeability, and the compressibility. For lower dosed powders, additional critical factors were observed like the wall friction angle, the tapped density, and the particle shape proved to be important factors [142]. These studies were complemented by Stranzinger et al., who investigated that higher filling speed, the compression ratio of dosing chamber to powder bed height (1:1, rather than $>1: 1)$, and smaller dosator size can result in an increasing filling weight variability in the case of low bulk density $(<45 \mathrm{~g} / \mathrm{mL})$ lactose with the particle size $<10 \mu \mathrm{m}$ [148]. Furthermore, Llusa et al., proved that high filling weight variability can result from the vibrations of the capsule-filling machine [149]. Therefore, minimizing the vibrations of the capsule-filling machine can improve filling weight variability.

\subsubsection{Capsule Fill Weight Effects}

The mass of dry powder filled into capsules is typically dependent upon the desired dose to be administered to patients; however, this may also have effects on the aerosol performance of the formulation. The weight of drug/formulation powder filled into the capsule causes the increase of the capsule weight initially, which contributes to the gravitational force of the filled capsule. Therefore, filling amount variation is thought to affect capsule motion profile within cDPIs, since capsule motion profile should be the outcome of the interplay between the aerosol flow force and the gravitational force of the filled capsule [79]. Heavier capsules tend to fall instead of moving inside the inhaler during aerosolization in comparison to lighter capsules. This tends to lower the velocity of the capsule movement [79]. As the powder is emitted from the capsule during inhalation, the capsule weight decreases second by second. This dynamic transformation leads to the continuous alteration of the gravitational force of the capsule. It is difficult to say at what point in time the scale changes enough to be negated by the forces due to airflow. When the initial powder filling weight is low, the changes in forces due to gravity can be negligible relative to airflow forces throughout an inhalation compared to higher fill weight capsules [147]. The degree to which there is a transitional difference remains to be investigated. One study from Ashkan et al., studied the effect of capsule filling weight on in vitro aerodynamic performance. They filled the capsules with different weights of micronized ibuprofen $(10 \mathrm{mg}, 25 \mathrm{mg}$, and $50 \mathrm{mg})$. As a result, they found that the ED value was independent of the alteration of capsule filling weight, while the increase in capsule filling weight led to largely decrease of FPF values [150].

\subsection{Capsule Storage Control}

It is well known that ambient factors can cause the denaturation of gelatin capsules. This is mostly due to the nature of gelatin, which can have decreases rigidity from undergoing gamma radiation [151], increases brittleness from incompatible solvents [152,153], 
hygroscopic fill [154], and is incompatible with reducing sugars, plasticizers, and preservatives [155]. In addition, having the proper relative humidity (RH) for storage is of great significance. RH can potentially change the original stiffness or hardness of the capsule [156]. Too low in RH gives rise to capsule brittleness [156], but too high of an RH brings about capsule stickiness $[46,157]$. Several studies have suggested that there was a correlation between the ambient moisture content and the piercing profile of the capsule in the device. Most notably, a higher penetration force was needed to puncture capsules stored in lower moisture environments for both HPMC and gelatin capsules [65]. Furthermore, Coulman's study showed a higher percentage of gelatin capsules with a 'regular' shaped puncture after removing the angular pin from punctured capsules if stored in desiccators with $\mathrm{Mg}\left(\mathrm{NO}_{3}\right)_{2}$ to create higher moisture contents. But no significant differences have been found between different HPMC capsules [58]. Also, RH within different capsules can play a role in the fluidization and dispersion of powders from within capsules. The formation of liquid bridges between formulation particles as well as the capsule wall results from high $\mathrm{RH}$. These liquid bridges create a binding capillary force that can lead to increased powder retention [158-160].

In addition to $\mathrm{RH}$, the ambient temperature also has the potential to fluctuate capsule stiffness and hardness [156]. Within Coulman's study, the author also simply looked at the relationship between the storage temperature and the puncturing characteristics, indicating that higher storage temperature tended to result in lower puncture forces as well as larger capsule puncture areas [58]. These reasons further add to the necessity for maintaining the storage conditions for capsules at reasonable moisture and temperature levels regarding strong quality control.

At the aspect of some preloaded capsules, chemical interaction may occur during storage if without consideration of incompatibility between capsule shells material and formulation components. An example is a highly moisture-sensitive drug, salicylic acid, which will degrade at high ambient humidity. One study found that the amount of salicylic acid degradation of salicylic acid was higher when stored in gelatin capsules vs. HPMC capsules at the initial time point (only slightly higher in gelatin than HPMC) and at 3, 6, 12, and 18 months when stored at $25^{\circ} \mathrm{C}$ at $60 \%$ relative humidity [161]. One explanation for this occurrence is the significantly higher moisture content in gelatin capsules versus HPMC hard capsules. Therefore, in cases where the drug is extremely sensitive to moisture, HPMCbased capsules may provide a better option for storage [62]. Also, when loading drugs that have a high sensitivity to oxidation careful attention needs to be made for capsule selection as HPMC capsules are known to be more permeable to oxygen than gelatin capsules. When comparing two films of HPMC and gelatin, each $100 \mu \mathrm{m}$ in thickness, the observed oxygen permeation values were $166 \mathrm{~cm}^{3} / \mathrm{m}^{2} /$ day and $3.41 \mathrm{~cm}^{3} / \mathrm{m}^{2} /$ day, respectively. This demonstrates a substantial difference that could ultimately affect the potency of the drug [62]. While this oxygen permeation can be a potential pitfall for the drug product, this effect can be mitigated by utilizing proper packaging and storage of the capsules before delivering the dose (e.g., the capsules can be stored in blister packaging and opened before administration).

This suggests that CPPs for inhalation capsule manufacturing involve several potential factors to be investigated like capsule coating, capsule filling method, capsule filling weight, weight variability, and storage $\mathrm{RH}$ and temperature control should be carefully considered in cDPIs product development.

\section{Conclusions}

The QbD framework is a valuable tool in pharmaceutical development for several years, which has been applied in many dosage form development programs. For the DPI product development, the scientific literature on $\mathrm{QbD}$ is still sparse. The major challenge for such products remains the multifactorial nature and complex interaction between formulation, primary packaging, and the device component. This review intends to provide information about aspects regarding the capsule component to be assessed when 
performing a QbD approach for cDPI products (Figure 1). In this work, we explored the interaction between capsule material properties, powder formulation properties, and device engineering and design which might have a direct impact on the product performance and hence, the therapeutic effect. Identification and understanding of the CQAs and CMAs will enable successful development and manufacturing in accordance with the QTPP. It will contribute to streamlining and de-risking new product development efforts in this field. Finally, it might serve as a roadmap for new and generic developments and support regulatory decisions, given the complexity of cDPI systems.

Author Contributions: Conceptualization, L.D., H.D.C.S. and S.S.; writing-original draft preparation, L.D. and S.V.J.; writing—-review and editing, L.D., A.D.B., S.S., S.V.J., M.J.H., J.K. and H.D.C.S.; visualization, L.D. All authors have read and agreed to the published version of the manuscript.

Funding: This research received no external funding.

Conflicts of Interest: H.D.C.S., an author of this paper, consults for and has equity ownership in Respira Therapeutics, Via Therapeutics, Nob Hill Therapeutics, and Cloxero Therapeutics on inhaled product development. A.B. holds stock in or is employed by CloXero Therapeutics and Via Therapeutics. The terms of the arrangement have been reviewed and approved by the University of Texas at Austin in accordance with its policy on objectivity in research. J.K., an author of this paper, is also an employee from ACG capsule company. Other authors declare no conflict of interest.

\section{References}

1. Van der Palen, J.; Klein, J.; Van Herwaarden, C.; Zielhuis, G.; Seydel, E. Multiple inhalers confuse asthma patients. Eur. Respir. J. 1999, 14, 1034-1037. [CrossRef]

2. Jarvis, S.; Ind, P.W.; Shiner, R.J. Inhaled Therapy in Elderly COPD Patients; Time for Re-Evaluation? Oxford University Press: Oxford, $\mathrm{UK}, 2007$.

3. Schuster, A.; Haliburn, C.; Döring, G.; Goldman, M.H.; Group, F.S. Safety, efficacy and convenience of colistimethate sodium dry powder for inhalation (Colobreathe DPI) in patients with cystic fibrosis: A randomised study. Thorax 2013, 68, 344-350. [CrossRef]

4. Ding, L.; Wang, J.; Cai, S.; Smyth, H.; Cui, Z. Pulmonary Biofilm-Based Chronic Infections and Inhaled Treatment Strategies. Int. J. Pharm. 2021, 604, 120768. [CrossRef] [PubMed]

5. Brunaugh, A.D.; Seo, H.; Warnken, Z.; Ding, L.; Seo, S.H.; Smyth, H.D.C. Development and Evaluation of Inhalable Composite Niclosamide-Lysozyme Particles: A Broad-Spectrum, Patient-Adaptable Treatment for Coronavirus Infections and Sequalae. PLOS ONE 2021, 16, e0246803. [CrossRef]

6. Klonoff, D.C. Afrezza Inhaled Insulin: The Fastest-Acting FDA-Approved Insulin on the Market Has Favorable Properties; SAGE: Los Angeles, CA, USA, 2014.

7. Anderson, P.J. History of aerosol therapy: Liquid nebulization to MDIs to DPIs. Respir. Care 2005, 50, 1139-1150.

8. Berkenfeld, K.; Lamprecht, A.; McConville, J.T. Devices for dry powder drug delivery to the lung. AAPS PharmSciTech 2015, 16, 479-490. [CrossRef] [PubMed]

9. Wauthoz, N.; Hennia, I.; Dejaeger, B.; Ecenarro, S.; Amighi, K. Proposed algorithm for healthcare professionals based on product characteristics and in vitro performances in different use conditions using formoterol-based marketed products for inhalation. Int. J. Pharm. 2017, 530, 415-429. [CrossRef]

10. Edwards, D. Applications of capsule dosing techniques for use in dry powder inhalers. Ther. Deliv. 2010, 1, 195-201. [CrossRef] [PubMed]

11. Chrystyn, H. The DiskusTM: A review of its position among dry powder inhaler devices. Int. J. Clin. Pract. 2007, 61, 1022-1036. [CrossRef] [PubMed]

12. Yang, M.Y.; Chan, J.G.Y.; Chan, H.-K. Pulmonary drug delivery by powder aerosols. J. Control. Release 2014, 193, 228-240. [CrossRef]

13. Islam, N.; Gladki, E. Dry powder inhalers (DPIs)—A review of device reliability and innovation. Int. J. Pharm. 2008, 360, 1-11. [CrossRef] [PubMed]

14. Birchall, J.; Jones, B.; Morrissey, A.; Jones, B. A comparison of the puncturing properties of gelatin and hypromellose capsules for use in dry powder inhalers. Drug Dev. Ind. Pharm. 2008, 34, 870-876. [CrossRef] [PubMed]

15. Muralidharan, P.; Hayes, D., Jr.; Mansour, H.M. Dry powder inhalers in COPD, lung inflammation and pulmonary infections. Expert Opin. Drug Deliv. 2015, 12, 947-962. [CrossRef]

16. Martinelli, F.; Balducci, A.G.; Rossi, A.; Sonvico, F.; Colombo, P.; Buttini, F. "Pierce and inhale" design in capsule based dry powder inhalers: Effect of capsule piercing and motion on aerodynamic performance of drugs. Int. J. Pharm. 2015, 487, 197-204. [CrossRef]

17. Elkins, M.R.; Robinson, P.; Anderson, S.D.; Perry, C.P.; Daviskas, E.; Charlton, B. Inspiratory flows and volumes in subjects with cystic fibrosis using a new dry powder inhaler device. Open Respir. Med. J. 2014, 8, 1. [CrossRef] [PubMed] 
18. Sanders, M. Inhalation therapy: An historical review. Prim. Care Respir. J. 2007, 16, 71. [CrossRef]

19. Bell, J.; Hartley, P.; Cox, J. Dry powder aerosols I: A new powder inhalation device. J. Pharm. Sci. 1971, 60, 1559-1564. [CrossRef]

20. Lawrence, X.Y.; Li, B.V. FDA Bioequivalence Standards; Springer: New York, NY, USA, 2014; Volume 13.

21. Weers, J.G.; Miller, D.P. Formulation design of dry powders for inhalation. J. Pharm. Sci. 2015, 104, 3259-3288. [CrossRef] [PubMed]

22. Donovan, M.J.; Kim, S.H.; Raman, V.; Smyth, H.D. Dry powder inhaler device influence on carrier particle performance. J. Pharm. Sci. 2012, 101, 1097-1107. [CrossRef]

23. Zhou, Q.T.; Tong, Z.; Tang, P.; Citterio, M.; Yang, R.; Chan, H.-K. Effect of device design on the aerosolization of a carrier-based dry powder inhaler-A case study on Aerolizer ${ }^{\circledR}$ Foradile $^{\circledR}$. AAPS J. 2013, 15, 511-522. [CrossRef]

24. Coates, M.S.; Chan, H.-K.; Fletcher, D.F.; Raper, J.A. Influence of air flow on the performance of a dry powder inhaler using computational and experimental analyses. Pharm. Res. 2005, 22, 1445-1453. [CrossRef]

25. Shetty, N.; Cipolla, D.; Park, H.; Zhou, Q.T. Physical stability of dry powder inhaler formulations. Expert Opin. Drug Deliv. 2020, 17, 77-96. [CrossRef]

26. de Boer, A.H.; Hagedoorn, P.; Hoppentocht, M.; Buttini, F.; Grasmeijer, F.; Frijlink, H.W. Dry powder inhalation: Past, present and future. Expert Opin. Drug Deliv. 2017, 14, 499-512. [CrossRef]

27. Levy, M.L.; Carroll, W.; Izquierdo Alonso, J.L.; Keller, C.; Lavorini, F.; Lehtimäki, L. Understanding Dry Powder Inhalers: Key Technical and Patient Preference Attributes. Adv Ther. 2019, 36, 2547-2557. [CrossRef] [PubMed]

28. Lavorini, F.; Pistolesi, M.; Usmani, O.S. Recent advances in capsule-based dry powder inhaler technology. Multidiscip Respir. Med. 2017, 12, 11. [CrossRef]

29. Mishra, V.; Thakur, S.; Patil, A.; Shukla, A. Quality by design (QbD) approaches in current pharmaceutical set-up. Expert Opin. Drug Deliv. 2018, 15, 737-758. [CrossRef] [PubMed]

30. Haleem, R.M.; Salem, M.Y.; Fatahallah, F.A.; Abdelfattah, L.E. Quality in the pharmaceutical industry-A literature review. Saudi Pharm. J. 2015, 23, 463-469. [CrossRef]

31. Buttini, F.; Rozou, S.; Rossi, A.; Zoumpliou, V.; Rekkas, D.M. The application of quality by design framework in the pharmaceutical development of dry powder inhalers. Eur. J. Pharm. Sci. 2018, 113, 64-76. [CrossRef]

32. Brunaugh, A.D.; Smyth, H.D. Formulation techniques for high dose dry powders. Int. J. Pharm. 2018, 547, 489-498. [CrossRef]

33. Seville, P.C.; Li, H.-y.; Learoyd, T.P. Spray-dried powders for pulmonary drug delivery. Crit. Rev. Ther. Drug Carr. Syst. 2007, 24, 307-360. [CrossRef]

34. Mansour, H.M.; Rhee, Y.S.; Wu, X. Nanomedicine in pulmonary delivery. Int. J. Nanomed. 2009, 4, 299-319. [CrossRef] [PubMed]

35. Brunaugh, A.D.; Sharma, S.; Smyth, H. Inhaled fixed-dose combination powders for the treatment of respiratory infections. Expert Opin. Drug Deliv. 2021, 18, 1-15. [CrossRef] [PubMed]

36. Dal Negro, R.W.; Turco, P.; Povero, M. Patients' usability of seven most used dry-powder inhalers in COPD. Multidiscip. Respir. Med. 2019, 14, 1-9.

37. Renswouw, D.C.V.; Laarhoven, A.C.V.; Haren, M.J.V.; Bouvy, M.L.; Weda, M. Storage instructions for inhalation capsules: Consequences of incorrect storage and adherence in daily practice. J. Pharm. Pract. 2010, 23, 548-552. [CrossRef]

38. Perera, A.D.; Kapitza, C.; Nosek, L.; Fishman, R.S.; Shapiro, D.A.; Heise, T.; Heinemann, L. Absorption and metabolic effect of inhaled insulin: Intrapatient variability after inhalation via the Aerodose insulin inhaler in patients with type 2 diabetes. Diabetes Care 2002, 25, 2276-2281. [CrossRef]

39. Lee, A.Y.; Cho, M.-H.; Kim, S. Recent advances in aerosol gene delivery systems using non-viral vectors for lung cancer therapy. Expert Opin. Drug Deliv. 2019, 16, 757-772. [CrossRef]

40. Wenzler, E.; Fraidenburg, D.R.; Scardina, T.; Danziger, L.H. Inhaled Antibiotics for Gram-Negative Respiratory Infections. Clin. Microbiol. Rev. 2016, 29, 581-632. [CrossRef] [PubMed]

41. Lawrence, X.Y.; Amidon, G.; Khan, M.A.; Hoag, S.W.; Polli, J.; Raju, G.; Woodcock, J. Understanding pharmaceutical quality by design. AAPS J. 2014, 16, 771-783.

42. Jones, B.E. Manufacture and Properties of Two-Piece Hard Capsules; Pharmaceutical Capsules, Pharmaceutical Press: London, UK, 2004; pp. 79-100.

43. Stegemann, S.; Connolly, P.; Matthews, W.; Barnett, R.; Aylott, M.; Schrooten, K.; Cadé, D.; Taylor, A.; Bresciani, M. Application of $\mathrm{QbD}$ principles for the evaluation of empty hard capsules as an input parameter in formulation development and manufacturing. AAPS PharmSciTech 2014, 15, 542-549. [CrossRef]

44. Mei, X.; Etzler, F.M.; Wang, Z. Use of Texture Analysis to Study Hydrophilic Solvent Effects on the Mechanical Properties of Hard Gelatin Capsules. Int. J. Pharm. 2006, 324, 128-135. [CrossRef]

45. Majee, S.B.; Avlani, D.; Biswas, G. HPMC as capsule shell material: Physicochemical, pharmaceutical and biopharmaceutical properties. Int. J. Pharm. Pharm. Sci. 2017, 9, 1-6. [CrossRef]

46. Chang, R.K.; Raghavan, K.S.; Hussain, M.A. A study on gelatin capsule brittleness: Moisture tranfer between the capsule shell and its content. J. Pharm. Sci. 1998, 87, 556-558. [CrossRef] [PubMed]

47. Stegemann, S. Non-Gelatin-Based Capsules. In Pharmaceutical Dosage Forms; CRC Press: London, UK, 2017 ; pp. 111-130.

48. Tan, S.; Newton, J. Influence of capsule dosator wall texture and powder properties on the angle of wall friction and powder-wall adhesion. Int. J. Pharm. 1990, 64, 227-234. [CrossRef] 
49. Heng, D.; Lee, S.H.; Ng, W.K.; Chan, H.-K.; Kwek, J.W.; Tan, R.B. Novel alternatives to reduce powder retention in the dry powder inhaler during aerosolization. Int. J. Pharm. 2013, 452, 194-200. [CrossRef]

50. Holgate, S. Inhaled sodium cromoglycate. Respir. Med. 1996, 90, 387-390. [CrossRef]

51. Saim, S.; Horhota, S.T. Process for overcoming drug retention in hard gelatin inhalation capsules. Drug Dev. Ind. Pharm. 2002, 28, 641-654. [CrossRef]

52. Araujo, R.; Soares, M.; Mazzei, J.L.; Ramos, M.; Siani, A.C. A Comparative Study of Hard Gelatin and Hypromellose Capsules Containing a Dry Extract of Senna (Cassia Angustifolia) under Controlled Temperature and Relative Humidity. Ind.J. Pharm. Sci. 2020, 82, 718-723.

53. Torrisi, B.M.; Birchall, J.C.; Jones, B.E.; Díez, F.; Coulman, S.A. The development of a sensitive methodology to characterise hard shell capsule puncture by dry powder inhaler pins. Int. J. Pharm. 2013, 456, 545-552. [CrossRef]

54. Testing and Comparison of Puncturing Forces for Gelatin and HPMC Inhalation Capsules. Available online: https://www. inhalationmag.com/wp-content/uploads/pdf/inh_20190601_0019.pdf (accessed on 1 April 2011).

55. Jones, B. Quali-V ${ }^{\circledR}$-I: A new key for dry powder inhalers. Drug Deliv. Technol. 2003, 3, 2-7.

56. Wauthoz, N.; Hennia, I.; Ecenarro, S.; Amighi, K. Impact of capsule type on aerodynamic performance of inhalation products: A case study using a formoterol-lactose binary or ternary blend. Int. J. Pharm. 2018, 553, 47-56. [CrossRef]

57. Podczeck, F. The strength and brittleness of hard shell capsules made from different materials. Bus. Brief. Pharm. Technol. 2002, 128-135.

58. Chong, R.H.; Jones, B.E.; Díez, F.; Birchall, J.C.; Coulman, S.A. Evaluating the sensitivity, reproducibility and flexibility of a method to test hard shell capsules intended for use in dry powder inhalers. Int. J. Pharm. 2016, 500, 316-325. [CrossRef]

59. Nakate, T.; Yoshida, H.; Ohike, A.; Tokunaga, Y.; Ibuki, R.; Kawashima, Y. Formulation development of inhalation powders for FK888 using the E-haler ${ }^{\circledR}$ to improve the inhalation performance at a high dose, and its absorption in healthy volunteers. Eur. J. Pharm. Biopharm. 2005, 59, 25-33. [CrossRef] [PubMed]

60. Benke, E.; Varga, P.; Szabó-Révész, P.; Ambrus, R. Stability and In Vitro Aerodynamic Studies of Inhalation Powders Containing Ciprofloxacin Hydrochloride Applying Different DPI Capsule Types. Pharmaceutics 2021, 13, 689. [CrossRef]

61. Telko, M.J.; Kujanpää, J.; Hickey, A.J. Investigation of triboelectric charging in dry powder inhalers using electrical low pressure impactor (ELPI ${ }^{\mathrm{TM}}$ ). Int. J. Pharm. 2007, 336, 352-360. [CrossRef]

62. Richardson, M. Impact of Capsule Selection on Formulation Stability in Dry Powder Inhalers (DPIs). 2011. Available online: https://www.inhalationmag.com/white-papers/capsugel/ (accessed on 1 April 2011).

63. Murachanian, D. An Introduction to Two-Piece Hard Capsules and Their Marketing Benefits. In Pharmaceutical Dosage Forms; CRC Press: London, UK, 2017; pp. 15-30.

64. Coates, M.S.; Fletcher, D.F.; Chan, H.-K.; Raper, J.A. The role of capsule on the performance of a dry powder inhaler using computational and experimental analyses. Pharm. Res. 2005, 22, 923-932. [CrossRef]

65. Kuentz, M.; Rothenhäusler, B.; Röthlisberger, D. Time domain 1H NMR as a new method to monitor softening of gelatin and HPMC capsule shells. Drug Dev. Ind. Pharm. 2006, 32, 1165-1173. [CrossRef] [PubMed]

66. Wachtel, H. Respiratory drug delivery. In Microsystems for Pharmatechnology; Springer: Cham, Switzerland, 2016; pp. 257-274.

67. Kondo, T.; Tanigaki, T.; Yokoyama, H.; Hibino, M.; Tajiri, S.; Akazawa, K.; Yamada, Y.; Cassan, S.M. Impact of holding position during inhalation on drug release from a reservoir-, blister-and capsule-type dry powder inhaler. J. Asthma 2017, 54, 792-797. [CrossRef]

68. Murachanian, D. Two-piece hard capsules for pharmaceutical formulations. J. GXP Compliance 2010, 14, 31.

69. Chew, N.Y.; Chan, H.-K. Influence of particle size, air flow, and inhaler device on the dispersion of mannitol powders as aerosols. Pharm. Res. 1999, 16, 1098-1103. [CrossRef]

70. Steckel, H.; Müller, B.W. In vitro evaluation of dry powder inhalers I: Drug deposition of commonly used devices. Int. J. Pharm. 1997, 154, 19-29. [CrossRef]

71. Coates, M.S.; Fletcher, D.F.; Chan, H.-K.; Raper, J.A. Effect of design on the performance of a dry powder inhaler using computational fluid dynamics. Part 1: Grid structure and mouthpiece length. J. Pharm. Sci. 2004, 93, 2863-2876. [CrossRef] [PubMed]

72. Tuteric, T.; Vulovic, A.; Cvijic, S.; Ibric, S.; Filipovic, N. Effect of Circulation Chamber Dimensions on Aerosol Delivery Efficiency of a Commercial Dry Powder Inhaler Aerolizer ${ }^{\circledR}$. In Proceedings of the 2017 IEEE 17th International Conference on Bioinformatics and Bioengineering (BIBE), Washington, DC, USA, 23-25 October 2017; pp. 555-558.

73. Shur, J.; Lee, S.; Adams, W.; Lionberger, R.; Tibbatts, J.; Price, R. Effect of device design on the in vitro performance and comparability for capsule-based dry powder inhalers. AAPS J. 2012, 14, 667-676. [CrossRef] [PubMed]

74. Benque, B.; Khinast, J.G. Understanding the motion of hard-shell capsules in dry powder inhalers. Int. J. Pharm. 2019, 567, 118481. [CrossRef]

75. Sim, S.; Margo, K.; Parks, J.; Howell, R.; Hebbink, G.A.; Orlando, L.; Larson, I.; Leslie, P.; Ho, L.; Morton, D.A. An insight into powder entrainment and drug delivery mechanisms from a modified Rotahaler ${ }^{\circledR}$. Int. J. Pharm. 2014, 477, 351-360. [CrossRef]

76. Behara, S.R.; Farkas, D.R.; Hindle, M.; Longest, P.W. Development of a high efficiency dry powder inhaler: Effects of capsule chamber design and inhaler surface modifications. Pharm. Res. 2014, 31, 360-372. [CrossRef]

77. Farkas, D.; Bonasera, S.; Bass, K.; Hindle, M.; Longest, P.W. Advancement of a Positive-Pressure Dry Powder Inhaler for Children: Use of a Vertical Aerosolization Chamber and Three-Dimensional Rod Array Interface. Pharm. Res. 2020, 37, 1-14. [CrossRef] 
78. Behara, S.R.; Longest, P.W.; Farkas, D.R.; Hindle, M. Development and comparison of new high-efficiency dry powder inhalers for carrier-free formulations. J. Pharm. Sci. 2014, 103, 465-477. [CrossRef]

79. Lefebvre, Y.; Barthes-Biesel, D. Motion of a Capsule in a Cylindrical Tube: Effect of Membrane Pre-Stress. J. Fluid Mech. 2007, 589, 157-181. [CrossRef]

80. Saleem, I.; Diez, F.; Jones, B.; Kayali, N.; Polo, L. Investigation on the aerosol performance of dry powder inhalation hypromellose capsules with different lubricant levels. Int. J. Pharm. 2015, 492, 258-263. [CrossRef]

81. Son, Y.-J.; Longest, P.W.; Tian, G.; Hindle, M. Evaluation and modification of commercial dry powder inhalers for the aerosolization of a submicrometer excipient enhanced growth (EEG) formulation. Eur. J. Pharm. Sci. 2013, 49, 390-399. [CrossRef]

82. Coates, M.S.; Chan, H.-K.; Fletcher, D.F.; Raper, J.A. Effect of design on the performance of a dry powder inhaler using computational fluid dynamics. Part 2: Air inlet size. J. Pharm. Sci. 2006, 95, 1382-1392. [CrossRef]

83. Chew, N.Y.; Chan, H.-K.; Bagster, D.F.; Mukhraiya, J. Characterization of pharmaceutical powder inhalers: Estimation of energy input for powder dispersion and effect of capsule device configuration. J. Aerosol Sci. 2002, 33, 999-1008. [CrossRef]

84. Behara, S.R.B.; Larson, I.; Kippax, P.; Morton, D.A.; Stewart, P. The kinetics of cohesive powder de-agglomeration from three inhaler devices. Int. J. Pharm. 2011, 421, 72-81. [CrossRef]

85. Weers, J.; Clark, A. The impact of inspiratory flow rate on drug delivery to the lungs with dry powder inhalers. Pharm. Res. 2017, 34, 507-528. [CrossRef] [PubMed]

86. Newman, S.P.; Chan, H.-K. In vitro/in vivo comparisons in pulmonary drug delivery. J. Aerosol Med. Pulm. Drug Deliv. 2008, 21, 77-84. [CrossRef] [PubMed]

87. Visser, J. Van der Waals and other cohesive forces affecting powder fluidization. Powder Technol. 1989, 58, 1-10. [CrossRef]

88. Tee, S.; Marriott, C.; Zeng, X.; Martin, G. The use of different sugars as fine and coarse carriers for aerosolised salbutamol sulphate. Int. J. Pharm. 2000, 208, 111-123. [CrossRef]

89. Edwards, D.; Dunbar, C. Therapeutic aerosol bioengineering. Annu. Rev. Biomed. Eng 2002, 4, 93-107. [CrossRef]

90. Bosquillon, C.; Lombry, C.; Preat, V.; Vanbever, R. Influence of formulation excipients and physical characteristics of inhalation dry powders on their aerosolization performance. J. Control. Release 2001, 70, 329-339. [CrossRef]

91. Brunaugh, A.D.; Wu, T.; Kanapuram, S.R.; Smyth, H.D. Effect of particle formation process on characteristics and aerosol performance of respirable protein powders. Mol. Pharm. 2019, 16, 4165-4180. [CrossRef]

92. Duong, T.; López-Iglesias, C.; Szewczyk, P.K.; Stachewicz, U.; Barros, J.; Alvarez-Lorenzo, C.; Alnaief, M.; García-González, C.A. A pathway from porous particle technology toward tailoring aerogels for pulmonary drug administration. Front. Bioeng. Biotechnol. 2021, 9, 323.

93. Brunaugh, A.D.; Jan, S.U.; Ferrati, S.; Smyth, H.D. Excipient-free pulmonary delivery and macrophage targeting of clofazimine via air jet micronization. Mol. Pharm. 2017, 14, 4019-4031. [CrossRef]

94. Ariane, M.; Sommerfeld, M.; Alexiadis, A. Wall collision and drug-carrier detachment in dry powder inhalers: Using DEM to devise a sub-scale model for CFD calculations. Powder Technol. 2018, 334, 65-75. [CrossRef]

95. Thornton, C.; Liu, L. How do agglomerates break? Powder Technol. 2004, 143, 110-116. [CrossRef]

96. Subero, J.; Ning, Z.; Ghadiri, M.; Thornton, C. Effect of interface energy on the impact strength of agglomerates. Powder Technol. 1999, 105, 66-73. [CrossRef]

97. Moreno, R.; Ghadiri, M.; Antony, S. Effect of the impact angle on the breakage of agglomerates: A numerical study using DEM. Powder Technol. 2003, 130, 132-137. [CrossRef]

98. Moreno-Atanasio, R.; Ghadiri, M. Mechanistic analysis and computer simulation of impact breakage of agglomerates: Effect of surface energy. Chem. Eng. Sci. 2006, 61, 2476-2481. [CrossRef]

99. Chan, H.-K. What is the role of particle morphology in pharmaceutical powder aerosols? Expert Opin. Drug Deliv. 2008, 5, 909-914. [CrossRef] [PubMed]

100. Smyth, H.D.; Hickey, A.J. Carriers in drug powder delivery. Am. J. Drug Deliv. 2005, 3, 117-132. [CrossRef]

101. Ellis, G. The maillard reaction. In Advances in Carbohydrate Chemistry; Elsevier: New York, NY, USA, 1959; Volume 14, pp. 63-134.

102. Görög, S. The Importance and the Challenges of Impurity Profiling in Modern Pharmaceutical Analysis; Elsevier: New York, NY, USA, 2006.

103. Flament, M.-P.; Leterme, P.; Gayot, A. The influence of carrier roughness on adhesion, content uniformity and the in vitro deposition of terbutaline sulphate from dry powder inhalers. Int. J. Pharm. 2004, 275, 201-209. [CrossRef]

104. Newman, S.; Busse, W. Evolution of dry powder inhaler design, formulation, and performance. Respir. Med. 2002, 96, 293-304. [CrossRef]

105. Adi, S.; Adi, H.; Chan, H.-K.; Tong, Z.; Yang, R.; Yu, A. Effects of mechanical impaction on aerosol performance of particles with different surface roughness. Powder Technol. 2013, 236, 164-170. [CrossRef]

106. Zeng, X.M.; Martin, G.P.; Marriott, C.; Pritchard, J. The effects of carrier size and morphology on the dispersion of salbutamol sulphate after aerosolization at different flow rates. J. Pharm. Pharmacol. 2000, 52, 1211-1221. [CrossRef]

107. Traini, D.; Young, P.M.; Thielmann, F.; Acharya, M. The influence of lactose pseudopolymorphic form on salbutamol sulfatelactose interactions in DPI formulations. Drug Dev. Ind. Pharm. 2008, 34, 992-1001. [CrossRef] [PubMed]

108. De Boer, A.; Hagedoorn, P.; Gjaltema, D.; Goede, J.; Kussendrager, K.; Frijlink, H. Air classifier technology (ACT) in dry powder inhalation Part 2. The effect of lactose carrier surface properties on the drug-to-carrier interaction in adhesive mixtures for inhalation. Int. J. Pharm. 2003, 260, 201-216. [CrossRef] 
109. French, D.L.; Edwards, D.A.; Niven, R.W. The influence of formulation on emission, deaggregation and deposition of dry powders for inhalation. J. Aerosol Sci. 1996, 27, 769-783. [CrossRef]

110. Telko, M.; Hickey, A. Aerodynamic and electrostatic properties of model dry powder aerosols: A comprehensive study of formulation factors. AAPS PharmSciTech 2014, 15, 1378-1397. [CrossRef]

111. Hamishehkar, H.; Rahimpour, Y.; Javadzadeh, Y. The Role of Carrier in Dry Powder Inhaler; InTech: New York, NY, USA, 2012; Volume 3.

112. Voss, A.; Finlay, W.H. Deagglomeration of dry powder pharmaceutical aerosols. Int. J. Pharm. 2002, 248, 39-50. [CrossRef]

113. Xu, Z.; Mansour, H.M.; Mulder, T.; McLean, R.; Langridge, J.; Hickey, A.J. Dry powder aerosols generated by standardized entrainment tubes from drug blends with lactose monohydrate: 1 . Albuterol sulfate and disodium cromoglycate. J. Pharm. Sci. 2010, 99, 3398-3414. [CrossRef]

114. Begat, P.; Morton, D.A.; Staniforth, J.N.; Price, R. The cohesive-adhesive balances in dry powder inhaler formulations I: Direct quantification by atomic force microscopy. Pharm. Res. 2004, 21, 1591-1597. [CrossRef]

115. Telko, M.J.; Hickey, A.J. Dry powder inhaler formulation. Respir. Care 2005, 50, 1209-1227. [PubMed]

116. Fowkes, F.M. Attractive forces at interfaces. Ind. Eng. Chem. 1964, 56, 40-52. [CrossRef]

117. Pilcer, G.; Wauthoz, N.; Amighi, K. Lactose characteristics and the generation of the aerosol. Adv. Drug Deliv. Rev. 2012, 64, 233-256. [CrossRef]

118. van Wachem, B.; Thalberg, K.; Remmelgas, J.; Niklasson-Björn, I. Simulation of dry powder inhalers: Combining micro-scale, meso-scale and macro-scale modeling. AIChE J. 2017, 63, 501-516. [CrossRef]

119. Podczeck, F.; Jones, B.E. Pharmaceutical Capsules; Pharmaceutical Press: London, UK, 2004.

120. Ayala, G.; Díez, F.; Gassó, M.T.; Jones, B.E.; Martín-Portugués, R.; Ramiro-Aparicio, J. Statistical tools and control of internal lubricant content of inhalation grade HPMC capsules during manufacture. Int. J. Pharm. 2016, 503, 36-40. [CrossRef]

121. Rhodes, C.T.; Banker, G.S. Modern Pharmaceutics; Marcel Dekker: New York, NY, USA, 2002.

122. Gullapalli, R.P.; Mazzitelli, C.L. Gelatin and non-gelatin capsule dosage forms. J. Pharm. Sci. 2017, 106, 1453-1465. [CrossRef] [PubMed]

123. Yamamoto, T.; Abe, K.; Matsuura, S. Hard Capsule for Pharmaceutical Drugs and Method for Producing the Same. U.S. Patent No. 5,431,917, 11 July 1993.

124. Cade, D.; Scott, R.; He, X. Polymer Film Compositions for Capsules. U.S. Patent No. US6,517,865B2, 11 February 2003.

125. Yang, J.H. Cellulose Capsule Using Mixed Solution of Pectin and Glycerin and the Manufacturing Process Thereof. U.S. Patent No. 6,410,050, 25 June 2002.

126. Al-Tabakha, M.M. HPMC capsules: Current status and future prospects. J. Pharm. Pharm. Sci. 2010, 13, 428-442. [CrossRef]

127. Djabourov, M.; Grillon, Y.; Leblond, J. The sol-gel transition in gelatin viewed by diffusing colloidal probes. Polym. Gels Netw. 1995, 3, 407-428. [CrossRef]

128. Haque, A.; Richardson, R.K.; Morris, E.R.; Gidley, M.J.; Caswell, D.C. Thermogelation of methylcellulose. Part II: Effect of hydroxypropyl substituents. Carbohydr. Polym. 1993, 22, 175-186. [CrossRef]

129. Sarkar, N. Thermal gelation properties of methyl and hydroxypropyl methylcellulose. J. Appl. Polym. Sci. 1979, $24,1073-1087$. [CrossRef]

130. Kalafat, J.; Powale, S.; Bhat, J.; Almeida, D.; Solanki, A. Impact of Different Capsules for Dry Powder Inhalation on Efficacy and Aerodynamic Performance of Salbutamol Inhalation Formulation. In Proceedings of the Drug Delivery to the Lung (DDL), Edinburgh, UK, 11-13 December 2019.

131. Diez, F.; Bhat, J.; Powale, S.; Almeida, D.; Kalafat, J. Impact of Internal Capsule Lubricant on the Aerosol Performance of Dry Powder Inhalers. In Proceedings of the Respiratory Drug Delivery (RDD), Lisbon, Portugal, 9-10 May 2019.

132. Lowell, J.; Rose-Innes, A. Contact electrification. Adv. Phys. 1980, 29, 947-1023. [CrossRef]

133. Stegemann, S. Improving Pulmonary drug delivery in Capsule Inhaler Systems: Optimizing capsule based on formulationcapsule-device interactions. In Respiratory Drug Delivery Asia 2014; RDD: Goa, India, 2014; pp. 1-8.

134. Bolhuis, G. Film formation by magnesium stearate during mixing and its effect on tabletting. Pharm. Weekblad. 1975, 110, 317-325.

135. Hussain, M.H.; York, P.; Timmins, P. A study of the formation of magnesium stearate film on sodium chloride using energydispersive X-ray analysis. Int. J. Pharm. 1988, 42, 89-95. [CrossRef]

136. Uzunović, A.; Vranić, E. Effect of magnesium stearate concentration on dissolution properties of ranitidine hydrochloride coated tablets. Bosn. J. Basic Med. Sci. 2007, 7, 279. [CrossRef]

137. Wang, J.; Wen, H.; Desai, D. Lubrication in tablet formulations. Eur. J. Pharm. Biopharm. 2010, 75, 1-15. [CrossRef]

138. Hindle, M.; Longest, P.W. Condensational growth of combination drug-excipient submicrometer particles for targeted highefficiency pulmonary delivery: Evaluation of formulation and delivery device. J. Pharm. Pharmacol. 2012, 64, 1254-1263. [CrossRef]

139. Longest, P.W.; Tian, G.; Li, X.; Son, Y.-J.; Hindle, M. Performance of combination drug and hygroscopic excipient submicrometer particles from a softmist inhaler in a characteristic model of the airways. Ann. Biomed. Eng. 2012, 40, 2596-2610. [CrossRef]

140. Small, L.E.; Augsburger, L. Instrumentation of an automatic capsule-filling machine. J. Pharm. Sci. 1977, 66, 504-509. [CrossRef]

141. Tan, S.; Newton, J. Powder flowability as an indication of capsule filling performance. Int. J. Pharm. 1990, 61, 145-155. [CrossRef] 
142. Faulhammer, E.; Llusa, M.; Wahl, P.; Paudel, A.; Lawrence, S.; Biserni, S.; Calzolari, V.; Khinast, J. Development of a design space and predictive statistical model for capsule filling of low-fill-weight inhalation products. Drug Dev. Ind. Pharm. 2016, 42, 221-230. [CrossRef]

143. Podczeck, F. The development of an instrumented tamp-filling capsule machine II: Investigations of plug development and tamping pressure at different filling stations. Eur. J. Pharm. Sci. 2001, 12, 515-521. [CrossRef]

144. Bryant, S.; Gill, I.; Edwards, D.; Smith, I.J. Advances in powder-dosing technology. Innov. Pharm. Technol. 2002, 124, 95-100.

145. Available online: https://www.capsugel.com/knowledge-center/xcelodose-s-powder-micro-dosing-system-brochure (accessed on 11 August 2019).

146. Freeman, T.; Moolchandani, V.; Hoag, S.; Fu, X. Capsule filling performance of powdered formulations in relation to flow characteristics. In Particulate Materials; RSC Publishing: New York, NY, USA, 2011; pp. 131-136.

147. Faulhammer, E.; Fink, M.; Llusa, M.; Lawrence, S.M.; Biserni, S.; Calzolari, V.; Khinast, J.G. Low-dose capsule filling of inhalation products: Critical material attributes and process parameters. Int. J. Pharm. 2014, 473, 617-626. [CrossRef] [PubMed]

148. Stranzinger, S.; Faulhammer, E.; Calzolari, V.; Biserni, S.; Dreu, R.; Šibanc, R.; Paudel, A.; Khinast, J. The effect of material attributes and process parameters on the powder bed uniformity during a low-dose dosator capsule filling process. Int. J. Pharm. 2017, 516, 9-20. [CrossRef]

149. Llusa, M.; Faulhammer, E.; Biserni, S.; Calzolari, V.; Lawrence, S.; Bresciani, M.; Khinast, J. The effect of capsule-filling machine vibrations on average fill weight. Int. J. Pharm. 2013, 454, 381-387. [CrossRef]

150. Yazdi, A.K.; Smyth, H.D. Carrier-free high-dose dry powder inhaler formulation of ibuprofen: Physicochemical characterization and in vitro aerodynamic performance. Int. J. Pharm. 2016, 511, 403-414. [CrossRef] [PubMed]

151. Fassihi, A.; Parker, M. Influence of gamma radiation on the gel rigidity index and binding capability of gelatin. J. Pharm. Sci. 1988, 77, 876-879. [CrossRef]

152. Tochio, S.; Nagata, S.; Yamashita, S. The influence of the composition of test fluids on dissolution from HPMC capsules. AAPS PharmSci 2002, 4, W4340.

153. Podczeck, F.; Jones, B.E. The in vitro dissolution of theophylline from different types of hard shell capsules. Drug Dev. Ind. Pharm. 2002, 28, 1163-1169. [CrossRef]

154. Bell, J.; Stevenson, N.; Taylor, J. A moisture transfer effect in hard gelatin capsules of sodium cromoglycate. J. Pharm. Pharmacol. 1973, 25, 96.

155. Missaghi, S.; Fassihi, R. Evaluation and comparison of physicomechanical characteristics of gelatin and hypromellose capsules. Drug Dev. Ind. Pharm. 2006, 32, 829-838. [CrossRef]

156. Kontny, M.J.; Mulski, C.A. Gelatin capsule brittleness as a function of relative humidity at room temperature. Int. J. Pharm. 1989, 54, 79-85. [CrossRef]

157. Geuns, E.R.; Toren, J.S.; Barends, D.M.; Bult, A. Decrease of the stage-2 deposition in the twin impinger during storage of beclomethasone dipropionate dry powder inhalers in controlled and uncontrolled humidities. Eur. J. Pharm. Biopharm. 1997, 44, 187-194. [CrossRef]

158. Young, P.M.; Price, R. The influence of humidity on the aerosolisation of micronised and SEDS produced salbutamol sulphate. Eur. J. Pharm. Sci. 2004, 22, 235-240. [CrossRef]

159. Price, R.; Young, P.; Edge, S.; Staniforth, J. The influence of relative humidity on particulate interactions in carrier-based dry powder inhaler formulations. Int. J. Pharm. 2002, 246, 47-59. [CrossRef]

160. Das, S.; Larson, I.; Young, P.; Stewart, P. Influence of storage relative humidity on the dispersion of salmeterol xinafoate powders for inhalation. J. Pharm. Sci. 2009, 98, 1015-1027. [CrossRef]

161. Nagata, S. Cellulosecapsules-Analternative To Gelatin. Biomed. Polym. Polym. Ther. 2001, 53, 53-62. 